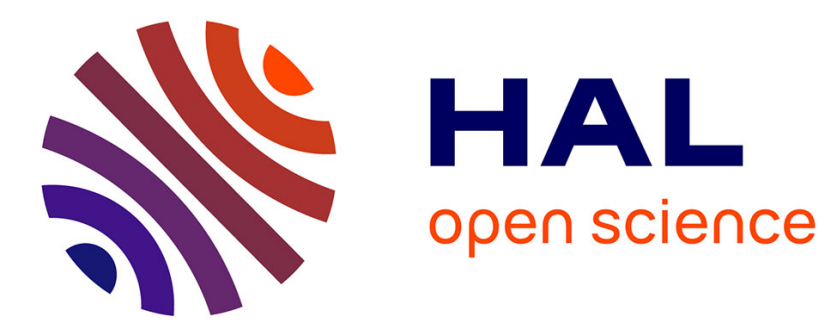

\title{
Endogenous firms' organization, internal audit and leniency programs
}

Emilie Dargaud, Armel Jacques

\section{To cite this version:}

Emilie Dargaud, Armel Jacques. Endogenous firms' organization, internal audit and leniency programs. 2015. halshs-01199268

\section{HAL Id: halshs-01199268 \\ https://shs.hal.science/halshs-01199268}

Preprint submitted on 15 Sep 2015

HAL is a multi-disciplinary open access archive for the deposit and dissemination of scientific research documents, whether they are published or not. The documents may come from teaching and research institutions in France or abroad, or from public or private research centers.
L'archive ouverte pluridisciplinaire HAL, est destinée au dépôt et à la diffusion de documents scientifiques de niveau recherche, publiés ou non, émanant des établissements d'enseignement et de recherche français ou étrangers, des laboratoires publics ou privés. 


\title{
GATE $_{\text {vossentromex }}$
}

UMR 5824

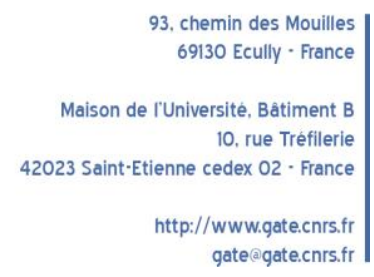

WP 1524 - September 2015

\section{Endogenous firms' organization, internal audit and leniency programs}

\author{
Emilie Dargaud, Armel Jacques
}

\begin{abstract}
:
When multi-product firms make simultaneous price-fixing agreements on different markets, they may wish to compartmentalize their agreements managing them with different individuals in order to avoid the contagion of antitrust authority investigations. Sometimes the leniency programs are effcient to defeat this strategy and to induce CEO to launch internal investigations and report the obtained hard evidence to the antitrust authority. However these programs may have pro-collusive effects for centralized firms.
\end{abstract}

\section{Keywords:}

Collusion, antitrust policy, leniency programs, multimarket contact, organizational form

JEL codes:

K42, L22, L41

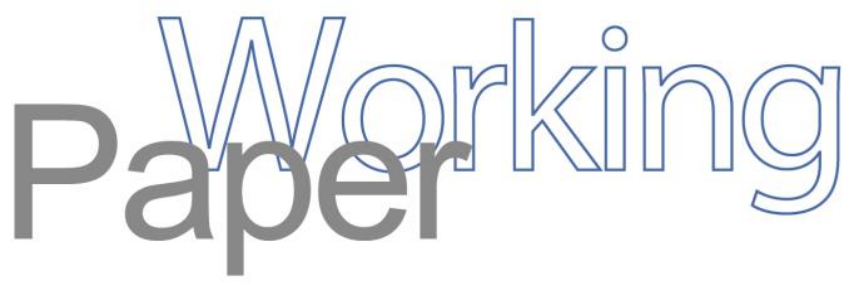




\title{
Endogenous firms' organization, internal audit and leniency programs*
}

\author{
Emilie DARGAUD ${ }^{\dagger} \quad$ Armel JACQUES ${ }^{\ddagger}$
}

7th September 2015

\begin{abstract}
When multi-product firms make simultaneous price-fixing agreements on different markets, they may wish to compartmentalize their agreements managing them with different individuals in order to avoid the contagion of antitrust authority investigations. Sometimes the leniency programs are efficient to defeat this strategy and to induce CEO to launch internal investigations and report the obtained hard evidence to the antitrust authority. However these programs may have pro-collusive effects for centralized firms.

Résumé : Lorsque des firmes multiproduits se livrent à des ententes en prix sur plusieurs marchés simultanément, elles peuvent souhaiter cloisonner les différents accords de collusion en les confiant à des managers de divisions afin d'éviter qu'une enquête antitrust dirigée contre l'un des accords, ne découvre les autres accords. Dans certains cas, les programmes de clémence se révèlent efficaces pour contrer cette stratégie et inciter les PDG des firmes à mener des audits internes pour trouver les preuves de l'existence de ces accords et à les transmettre à l'autorité de la concurrence. Cependant, ces programmes de clémence peuvent parfois renforcer les possibilités de collusion des firmes plus centralisées et se traduire par une extension de la collusion.
\end{abstract}

Keywords: Collusion, antitrust policy, leniency programs, multimarket contact, organizational form.

JEL: K42, L22, L41.

\footnotetext{
*An earlier version of this paper was presented in the AFSE congress, Lyon 2014. We thank participants for helpful comments and discussion.

†Université de Lyon, Lyon, F-69007, France ; CNRS, GATE Lyon Saint-Etienne, Ecully, F-69130, France ; Université Lyon 2, Lyon, F-69007, France. E-mail: dargaud@gate.cnrs.fr.

${ }^{\ddagger}$ CEMOI, Université de La Réunion, Faculté de Droit et d'Economie, 15, avenue René Cassin, 97715 Saint-Denis messag cedex 9. Email : Armel.Jacques@univ-reunion.fr.
} 


\section{Introduction}

Colluding firms run some risk of being caught by the antitrust authority or denounced by theirs clients. Multiproducts firms which engage in several different markets face additional risk of being caught participating in one cartel whilst being investigated in relation to another which is particularly strong. According to Hammond (2009): "over half of these investigations [involving international cartels] were initiated as a result of leads generated during an investigation of a completely separate market". However firms can reduce this risk by adjusting their strategies. They may cancel this risk if they do not collude simultaneously on several markets. ${ }^{1}$ They can also adopt a decentralized organization in which prices of collusive agreements inside the same firm are decided by several managers with no direct link between them. ${ }^{2}$

This idea is developed in Dargaud and Jacques (2015) [DJ]. They suggest that if the firms compartmentalize collusive agreements then the probability that antitrust authority uncovers inculpatory evidence of several infringements when it investigates only one market is decreased. ${ }^{3}$ DJ consider a framework with two firms, each of which produces two substitute goods. They show that if the two products are close substitutes, competition between the two divisions of a multi divisional firm [M-form] results in low collusive prices which leads firms to choose the unitary structure [U-form] despite the increased risk of fine. But if products are weak substitutes firms adopt the M-form structure. ${ }^{4}$ In this case the CEOs assign the task to negotiate the separate collusive agreements to their divisional managers who are cut off from each other. DJ does not address the role of leniency programs which are widely used as part of antitrust authority. ${ }^{5}$ But we can find examples where firms engaged in multi-markets collusive agreements apply for leniency as was the case for the SC Johnson firm. This firm blew the whistle in December 2005 on a cartel concerning household goods and insecticides. Then the french antitrust authority burst into a meeting of the managers of the collusive agreements. Simultaneously the authority raided the head office of the firms involved, among them was Colgate-Palmolive. This last firm applied twice for leniency. The first application concerned the investigated cartel but the second concerned an undetected cartel on body-care goods. ${ }^{6}$

This article analyzes if leniency programs can be used in order to defeat the compartmentalization strategy.

\footnotetext{
${ }^{1}$ Choi and Gerlach (2013) show that firms may choose a sequential strategy in which they collude on one market then on an other after the first cartel was dissolved.

${ }^{2}$ Some works dealing with organized crime examine the role which information exchange plays inside a criminal organization. Garoupa (2007) studies the tradeoff between a greater efficiency of more informed agents and the risk for the chief of being accused after an agent is arrested. Baccara and Bar-Isaac (2008) suggest that members of a criminal organization may keep incriminating documents for other members in order to facilitate internal cooperation. The threat of being exposed induces agents not to deviate from the cooperation agreement.

${ }^{3}$ DJ illustrate this point by contrasting ADM and Akzo Nobel N.V. firms. ADM was a very centralized firm (Connor, 1997). The documents taken by the FBI during the investigation of the lysine cartel also revealed other wrongdoing particularly an amino acid cartel and a citric acid cartel. In contrast Akzo Nobel N.V. had many subsidiaries. One of its was implicated in the Choline Chloride cartel until 1998 despite investigations on Gluconate cartel started in 1995.

${ }^{4}$ Baker and Faulkner (1993) reconstruct actual communication networks in 1950s involved in conspiracies in the heavy electrical equipment collusive industry in the USA. They identify the need of coordination as a barrier of compartmentalization of the individuals involved in several agreements.

${ }^{5}$ See Spagnolo (2008) for a literature review on leniency and Miller (2009) and Brenner (2009) for empirical studies in US and $\mathrm{EU}$ on this subject.

${ }^{6}$ The vitamins cartel is another example in which leniency facilitated detection of some cartels after an investigation in other cartels. A third example is in the number 15-D-03 decision of the french competition authority: after an investigation within the Senagral company about a cartel concerning dairy products sold under retailers' private labels, this company applies for leniency for a second cartel concerning moulded cheese.
} 
In particular we consider whether or not leniency and US amnesty plus programs can be used by the antitrust authority to induce $\mathrm{CEO}$ of decentralized firms to conduct internal audit and denounce price-fixing agreements established by the managers. In this case they may receive reduced fine on the investigated cartel (simple leniency programs) or for another cartel under advanced investigation (amnesty plus). The answers largely depend on the characteristics of leniency programs, the detection probability on the second cartel during investigation on the first cartel and the timing. Two timings are analyzed, the main difference being in the possibility or not for the firm to apply for leniency from the times an investigation is launched on the first cartel to the possible detection of the second cartel by serendipity. We call scenario S (for Short investigation) when firms lack the time to apply for leniency for the second cartel before its detection and scenario L (Long investigation) the opposite situation.

In scenario S simple leniency programs (without amnesty plus) do not fundamentally alter firms' strategies. Particularly the CEOs of decentralized firms are not induced to launch investigations and report evidence of a second cartel to antitrust authority. More precisely in the case they are tempted to report evidence of the second cartel they lack ability and when they can they are not induced to do this. However leniency may modify collusion sustainability: firms can deviate from the agreement and simultaneously apply for leniency resulting in increased deviation profit. Leniency can also impact the firms' internal structure if collusion is sustainable only with one type of internal organization.

In scenario L the impact of the simple leniency programs on decentralized firms depends on the level of compartmentalization. In the case there is perfect compartmentalization CEOs are not induced to search evidence of the second cartel and the decentralization strategy is not altered by the leniency programs. But if the compartmentalization is not perfect the CEOs can be induced to launch investigation and report evidence of the second cartel before its detection. According to the parameters values and particularly the successful of internal audit, managers can decide to cooperate with the CEO by passing on hard evidence otherwise they can try to hide it and continue to collude on the second market. Sometimes, the leniency programs can be used by the authority to defeat the decentralization strategy but it is not always socially better. Expected profits of decentralized colluding firms are decreased by the leniency but it is not always the case for centralized firms since the conviction of the second cartel is inescapable. Firms can apply for leniency for the second cartel and expected fine is then reduced. Allowing leniency applications during the investigation process can lead to anti-competitive effect since it may extend possibility for centralized firms to make collusive agreements.

Effects of amnesty plus programs ${ }^{7}$ also depend on the duration of investigations. Roux and Von UngernSternberg (2007), Lefouili and Roux (2012) and Marx, Mezzetti and Marshall (2015) reveal that theses programs lead to ambiguous effects on collusion. ${ }^{8}$ We reach the same ambiguous effects in this paper.

\footnotetext{
${ }^{7}$ These US programs established in 1999 and not adopted by the European Commission consist of reduced fines for already convinced firm if it reports another undetected cartel to the antitrust authority.

${ }^{8}$ Roux and Von Ungern-Sternberg (2007) analyze the effects of amnesty plus in a static framework. Firms can reveal the second cartel to benefit from a reduced fine concerning the first one. But in some cases firms do not reveal a cartel since the disclosure of the first cartel may induce them to reveal the second one. Firms do not reveal the first one to maintain the second one so the amnesty plus program may lead to pro-collusive effect.

Marx, Mezzetti and Marshall (2015) also use a static framework for analyzing penalty plus programs. When a first cartel is
} 
The presence of amnesty plus strongly affects the choice of decentralized structure in order to continue the collusion in the second market after the first one has been detected. But pro-collusive effect appears for centralized firms simultaneously colluding in the two markets in scenario L+ (scenario L with amnesty plus). Then amnesty plus may drive firms to adopt centralized structure. The destabilizing effect on the strategy involving firms to choose decentralized organization can be softened if the decentralization enables managers to hide the information not only to the antitrust authority but to the CEOs. ${ }^{9}$

The paper is organized as follows. In section 2 we describe our model. Section 3 reports the major results obtained by DJ without leniency programs. These results serve as a benchmark to analyze effects of leniency. In section 4 effects of leniency are characterized considering the same restrictions on parameters as in DJ and distinguishing two timings concerning the application of leniency. Section 5 introduces the amnesty plus programs, considering also the two timings of the game. We study several extensions in section 6 to check the robustness of the results. Particularly the restrictions on parameters are relaxed. The conclusion follows in section 7 .

\section{The model}

Our model is similar to that developed by DJ, irrespective of the fact that the leniency programs [LP] are introduced. Two identical firms 1 and 2 produce both two differentiated products $\mathrm{A}$ and $\mathrm{B}$ with the same marginal cost which is assumed to be zero. These two firms play an infinitely repeated game of price competition. We consider a third player: the antitrust authority intended to fight collusion.

Organizational design: Before competing in price, firms determine their organizational form. Each firm can adopt a centralized/unitary organizational structure (U-form) or a decentralized/multidivisional structure (M-form). In the first case each CEO chooses prices in order to maximize the overall profit for his firm whereas in the second option, two divisional managers determine each one the prices of single product, maximizing

convicted, firms under the penalty plus program are asked if they collude on other markets. If firms choose not to apply for leniency at this moment, they no longer can apply for leniency when an investigation is opened on an other cartel. Authors show that the incentives to apply for leniency for the second cartel when the first is convicted are low because firms do not know if an investigation will be opened on this second cartel (so the probability to be convicted is low). So firms choose not to apply for leniency and the effect of penalty plus programs is to cancel the possibility to apply for leniency later and to increase the expected profits of colluding firms.

Lefouili and Roux (2012) use a dynamic framework. The amnesty plus affects collusive strategies under which firms cooperate and never denounce the existing cartels. But the amnesty plus makes more attractive collusive strategies ensuring that the second cartel is revealed after the first one is detected. So the amnesty plus destabilizes collusive strategies under which firms continue to collude after the detection and the condemnation of the first cartel (pro-competitive effect) but facilitates collusive strategies in which firms reveal the second cartel after the detection and the condemnation of the first cartel (pro-collusive effect).

${ }^{9}$ Under decentralized organization, managers are not generally induced to reveal the information to authority even if there is an amnesty plus program. Indeed manager operating in the investigated market no longer has information to reveal to the authority in exchange for reduced fine since decentralization compartmentalizes agreements and leads to hide proofs. The manager operating in the other market holds the evidence but is not induced to reveal it since the reduced fine is not about its own division. Consequently managers have a common interest to not apply for leniency. By contrast, CEOs maximising the global profit of the firm can profit from revealing the undetected second cartel in order to benefit from the amnesty plus program. But they need hard evidence. Under decentralized organization CEOs can obtain these proofs by conducting internal audit. If the success probability of the audit is high then the amnesty plus affects the collusive strategies based on decentralized organizations. But in the opposite case decentralization can decrease the destabilizing effects of the amnesty plus program. 
the profit of their own divisions. The organization's choice is cooperative. ${ }^{10}$

Price competition: Once the organizational structures are decided, firms play an infinitely repeated game of price competition. At each period, firms can decide to reach a collusive agreement on one or two products. The collusion outcomes are modelled on a grim trigger basis: as soon a firm deviates from the agreement, all other firms will play non-cooperatively forever. Both firms have the same discount rate $\delta$.

The demands for products A and B are characterized by the following functions (the parameter $d$ reflects the substitutability of the products): ${ }^{11}$

$$
\begin{aligned}
& Q^{A}\left(p^{A}, p^{B}\right)=\max \left\{0, \min \left\{a-p^{A}+d\left(p^{B}-p^{A}\right), \frac{1+2 d}{1+d}\left(a-p^{A}\right)\right\}\right\} \\
& Q^{B}\left(p^{A}, p^{B}\right)=\max \left\{0, \min \left\{a-p^{B}+d\left(p^{A}-p^{B}\right), \frac{1+2 d}{1+d}\left(a-p^{B}\right)\right\}\right\}
\end{aligned}
$$

Probabilities of detection and fine: Collusion among firms or divisions inside the firms generates hard evidences which can be found by the authority with probability $\rho$. The authority can still find collusion during a deviation period but past offence can not be detected any more once firms have reverted to competitive pricing. If a cartel is detected, the authority launches an investigation which leads to successful prosecution with probability $\mu_{1}=1$ and a fine $F$ is imposed on each cartel member. Cartels are dissolved once they have been condemned and firms can not collude again on a condemned market. During this one-market investigation, the authority may find cogent evidence of a collusive agreement in the other market. The probability of this depends on the organizational structure of the firms: it is equal to $\mu_{2}$ if the two firms are centralized, $\mu_{3}$ if they are decentralized and $\mu_{4}$ if we consider an asymmetric organizational structure. In a case of successful prosecution firms must pay a second fine $F$. We assume that: $\mu_{2} \geq \mu_{3}$. Decentralization compartmentalizes collusive agreements into different divisions and then reduces the probability that the authority will find hard evidence of a second cartel when it investigates in only one market. We also assume that $\mu_{4}=\mu_{2}$. This assumption implies that the asymmetric case may be disregarded in the paper as it is always dominated by the U-form symmetric case. ${ }^{12}$

Timing of the leniency programs: Firms can apply for leniency at various times. The first one is before the detection of collusive agreements. When a firm deviates from the cartel, it has incentive to simultaneously apply for the leniency since the authority can still find collusion during this deviation period. Thus leniency yields to higher profit for deviating firms. In some models, firms can apply for leniency after a cartel is detected but before it is condemned, but since $\mu_{1}=1$ authority should not propose leniency during this

\footnotetext{
${ }^{10}$ Alternatively we could assume that firms sequentially choose their organizational design. We will choose later assumptions which imply that the two firms will always select the same organizational structure in a pure strategy Nash perfect equilibrium. The choice of organizational structure is like a coordination game in which firms are supposed to coordinate in the best equilibrium as they cooperate or they sequentially choose their organizational design.

${ }^{11}$ The "usable" component of the functions is $a-p^{A}+d\left(p^{B}-p^{A}\right)$. The other part $\frac{1+2 d}{1+d}\left(a-p^{A}\right)$ is equivalent to the demand of the product $\mathrm{A}$ when the price of $\mathrm{B}$ is sufficiently high to have zero demand, but it is not an equilibrium situation.

${ }^{12}$ We assume that $\rho, \mu_{1}, \mu_{2}, \mu_{3}$ and $\mu_{4}$ are not altered when the LP are introduced. Harrington and Chang (2012) analyze a probability of detection varying with the number of cases investigated by the antitrust authority and hence with the introduction of the LP.
} 
period. So we do not consider this possibility. ${ }^{13}$ A third possibility is to consider that firms apply for leniency between the prosecution of the first cartel and the detection of the second by serendipity. Two assumptions will be studied. In scenario $S$ (Short investigations) the detection of the second cartel comes shortly after the detection of the first and then firms can not apply for leniency for this second cartel. ${ }^{14}$ In scenario $L$ (Long investigations) firms can apply for leniency for the second cartel after the detection of the first one. ${ }^{15}$ Finally it is possible for the firms to apply for leniency after completion of the investigation if the second cartel has not been detected.

Chronology of each period: The chronology of each period is: (1) the firms choose their prices. (2) They can apply for leniency. (3) They observe all the prices. (4) The authority suspects cartel with probability $\rho$. (5) The authority successfully prosecutes the detected cartel. (6) In scenario $L$ (but not in scenario $S$ ) firms can apply for leniency for the second cartel. (7) The authority detects and prosecutes the second cartel with probability $\mu_{2}$ or $\mu_{3}$ (according to the choice of organizational structure). (8) The firms can apply for leniency if this second cartel has not been detected by the authority.

Reduced fines with the LP: If only one firm applies for leniency before the cartel is detected it obtains total immunity from fines. When applicants simultaneously apply, the firm obtaining total immunity from fines is randomly chosen so each firm has to pay an expected fine of $0.5 F .{ }^{16}$ Offering the possibility of total immunity at stage (2) is optimal since the deviation profit of the firms is maximized and this weakens collusive sustainability. ${ }^{17}$ Moreover total immunity is also proposed for the second cartel in stage (6) (under Long investigations) and in stage (8). It is not always optimal but this assumption removes introduction of an additional parameter and it seems to be the usual practice of the antitrust authorities. ${ }^{18}$

In 1999 the US has adopted the Amnesty Plus program which consists of reduced fines for already convinced firm if this firm reports an other undetected cartel to the authority. We introduce this program in section 5. Applying for leniency during stages (6) or (8) allows firms to obtain total immunity from fines for the second cartel but also reduced fine for the first cartel of $(1-\tau) F$, with $\tau<1$. Once again only the first firm benefits from reduced fine. We refer to the scenarios $S+$ and $L+$ when amnesty plus is introduced.

Who can apply for leniency? Under the centralized structure the CEOs have clear evidence concerning both cartels and they can apply for leniency. It is more ambiguous under the decentralized structure. Collusive agreements are organized by managers who have proofs for their own cartel. We assume that CEO

\footnotetext{
${ }^{13}$ Firms can never apply for leniency for the first cartel after its detection. The major reason of the leniency application studied by Motta and Polo (1993) is then rejected.

${ }^{14} \mathrm{It}$ is the case for instance if the investigations provide evidences about the two cartels.

${ }^{15}$ The example cited in the introduction seems consistent with this scenario. Colgate-Palmolive has had time to apply for leniency for the second cartel before its detection by the antitrust authority.

${ }^{16}$ Sauvagnat (2014) suggests that total immunity from fines be implemented if only one firm applies for leniency. If there is more than one applicant (applying simultaneously) the reduction from fines is negligible. Traditional approach is considered in our paper.

${ }^{17}$ See Spagnolo (2005) and Harrington (2008). We do not introduce the possibility for the antitrust authority to reward informed employees reporting evidence as was the case in Aubert, Rey and Kovacic (2006).

${ }^{18}$ Colgate-Palmolive has benefited from total immunity on the second revealed cartel.
} 
can launch internal audits in order to gather evidence and apply for leniency. The cost of an audit is assumed to be $k$ and the CEO obtains hard evidences with probability $\sigma$ if managers do not cooperate. Managers may also voluntarily present information about the cartels to their CEO. The different incentives to apply for leniency by the managers and the CEO are discussed in section 5.

\section{Benchmark case: no LP}

This section presents the main results of DJ obtained without LP. They will be used for comparison throughout this paper. As in DJ we assume that the probability of contagion of antitrust authority investigations is equal to zero if firms are decentralized $\left(\mu_{3}=0\right)$ and one in the opposite case $\left(\mu_{2}=1\right)$. We postpone the study of the cases $\mu_{3}>0$ and $\mu_{2}<1$ until section 6 .

Strategies of centralized firms: Centralized firms have two different cartel options. The first is to simultaneously collude in the two markets $\left(U_{\text {sim }}\right.$ strategy). The second is to sequentially collude in the two markets $\left(U_{s e q}\right.$ strategy): the firms initiate a cartel concerning one market and then initiate collusion in the second market once the first cartel has been detected. ${ }^{19}$

The $U_{s i m}$ strategy produces expected discounted value of a colluding firm which is $\Pi_{i}^{U_{s i m}}=\frac{\pi_{i}^{c U}-2 \rho(2-\rho) F}{1-\delta(1-\rho)^{2}}$, with $\pi_{i}^{c U}=\frac{a^{2}}{4}$ is the per-period profit of each colluding firm. ${ }^{20}$ Collusion in both markets is sustainable if and only if the fine per product imposed on each firm does not exceed the following threshold value: $F_{U_{\text {sim }}}=\frac{\delta(1-\rho)^{2}-\frac{1}{2}}{\delta(1-\rho)^{2} \rho(2-\rho)} \pi_{i}^{c U}$.

The expected payoff of the collusive firm under the second strategy is: $\Pi_{i}^{U_{s e q}}=\frac{(1-\delta+2 \delta \rho)\left(\widetilde{\pi}_{i}^{c}-\rho F\right)}{[1-\delta(1-\rho)]^{2}}$, with $\tilde{\pi}_{i}^{c}=\frac{a^{2}}{8(1+d)}$ is the per-period payoff of each firm associated with collusion. We obtain two conditions of sustainability. The first condition concerns the second cartel and is defined with the following threshold value of the fine: $\widetilde{F}=\frac{2 \delta(1-\rho)-1}{\delta \rho(1-\rho)} \widetilde{\pi}_{i}^{c}$. The second condition concerns the first cartel accounting the expected collusive outcome in the second cartel once the first cartel is detected. The threshold value of the fine is then: $F_{U_{s e q}}=\frac{-1+3 \delta-2 \delta \rho-2 \delta^{2}(1-\rho)^{2}}{\left[1-\delta(1-\rho)^{2}\right] \delta \rho} \tilde{\pi}_{i}^{c}$. Intuitively, this condition is easier to sustain than: $F \leq \widetilde{F}$.

When both strategies are sustainable, the simultaneous case dominates sequential cartels if and only if:

$$
\Pi_{i}^{U_{s i m}} \geq \Pi_{i}^{U_{s e q}} \Leftrightarrow F \leq \frac{[1-\delta(1-\rho)]^{2} \pi_{i}^{c U}-\left[1-\delta(1-\rho)^{2}\right](1-\delta+2 \delta \rho) \tilde{\pi}_{i}^{c}}{\left\{3-2 \rho-\delta \rho+(3 \rho-6) \delta(1-\rho)+3 \delta^{2}(1-\rho)^{2}\right\} \rho} \equiv F_{1}
$$

Strategies of decentralized firms: Decentralized firms face two different cartel options. The two firms simultaneously collude in the two markets, then when a cartel has been successfully detected in only one

\footnotetext{
${ }^{19}$ We prove in DJ that firms never collude in only one market and stop colluding once they are fined.

${ }^{20}$ We prove in DJ that colluding firms always choose the monopoly price. This outcome is due to three assumptions. (1) Firms produce homogeneous goods on each market. (2) The detection probability does not depend on the firms' prices or the prices variations. (3) The fine is independent of the collusive price.

If the detection probability depends on collusive price or price variations then the cartel could adopt a price below the monopoly price (Harrington, 2004 and 2005, Houba, Motchenkova and Wen, 2012). Cartel can also choose a lower price if the expected fine depends on collusive price (Souam, 2001).
} 
market, firms can either continue to collude in the other market ( $M c$ strategy) or can stop $\left(M s\right.$ strategy). ${ }^{21}$ The present discounted value of a division from colluding under the $M s$ strategy is: $\Pi_{i}^{M s}=\frac{\pi_{i}^{c M}-\rho F}{1-\delta(1-\rho)^{2}}$, with $\pi_{i}^{c M}=\frac{1+d}{2(2+d)^{2}} a^{2}$ is the per-period collusive profit of each division. ${ }^{22}$ This collusive strategy is sustainable if and only if: $F \leq F_{M s}=\frac{2 \delta(1-\rho)^{2}-1}{\delta(1-\rho)^{2} \rho} \pi_{i}^{c M}$. Under the $M c$ strategy the present discounted value of a division from colluding is: $\Pi_{i}^{M c}=\frac{\pi_{i}^{c M}-\rho F+\delta(1-\rho) \rho \widetilde{\Pi}_{i}}{1-\delta(1-\rho)^{2}}$, with $\widetilde{\Pi}_{i}=\frac{\widetilde{\pi}_{i}^{c}-\rho F}{1-\delta(1-\rho)}$ is the present discounted value of a division under collusion in only one market after the other cartel has been discovered. This collusive strategy is sustainable if and only if: $F \leq F_{M c}=\frac{[1-\delta(1-\rho)]\left[2 \delta(1-\rho)^{2}-1\right] \pi_{i}^{c M}+\delta \rho(1-\rho) \widetilde{\pi}_{i}^{c}}{\left[1-\delta(1-\rho)^{2}\right] \delta \rho(1-\rho)}$ and $F \leq \widetilde{F}$. The first condition is less restrictive than the second one. Decentralized firms choose the $M c$ strategy if it is sustainable: $F \leq \widetilde{F}$.

Equilibrium organization choice: Comparison of the profits is used to endogenize the choice of organizational structure. Firms adopt the $U_{\text {sim }}$ strategy instead of the $M c$ strategy if and only if:

$$
\Pi_{i}^{U_{s i m}} \geq 2 \Pi_{i}^{M c} \Leftrightarrow F \leq \frac{[1-\delta(1-\rho)]\left(\frac{\pi_{i}^{c U}}{2}-\pi_{i}^{c M}\right)-\delta(1-\rho) \rho \widetilde{\pi}_{i}^{c}}{(1-\delta)(1-\rho) \rho} \equiv F_{2}
$$

Firms adopt the $U_{\text {sim }}$ strategy instead of the $M s$ strategy if and only if:

$$
\Pi_{i}^{U_{s i m}} \geq 2 \Pi_{i}^{M s} \Leftrightarrow F \leq \frac{\frac{\pi_{i}^{c U}}{2}-\pi_{i}^{c M}}{(1-\rho) \rho} \equiv F_{3}
$$

Proposition 1 If $\widetilde{F}>F>F_{2}$, firms choose the $M c$ strategy. If $F_{M s}>F>\max \left(\widetilde{F}, \min \left(F_{3}, F_{U_{s i m}}\right)\right)$, firms choose the $M s$ strategy. In the other cases where $F<F_{U_{\text {sim }}}$, firms choose the $U_{\text {sim }}$ strategy. Firms do not collude if $F>\max \left(\widetilde{F}, F_{M s}, F_{U_{s i m}}\right)$.

Figure 1 graphically illustrates these results $(a=10, \rho=0.01$ and $\delta=0.8) .{ }^{23}$

If goods are independent, firms compartmentalize activities even if the fine is nil. In this case, the lack of coordination between divisions has no impact on equilibrium prices and firms still collude in one market if a cartel has been discovered in the other. If goods are substitutable, compartmentalization yields competition between divisions of the same firm, therefore equilibrium prices and profits are lower on the collusive path. Intra-firm competition increases with $d$ and firms switch to a centralized organization and $U_{\text {sim }}$ strategy if $d$ is sufficiently high. ${ }^{24}$ The level of fine influences the choice of organizational structure. If it is high, firms may prefer the decentralized structure to avoid the risk of double penalty.

If goods are weak substitutes, intra-firm competition is low and firms choose decentralized organization to continue collusion in the second market once the first cartel had been detected (in $M c$ zone) or to avoid a double fine (in $M s$ zone).

\footnotetext{
${ }^{21}$ Two other strategies could be considered in which firms start collusion on only one market, but we prove in DJ that only simultaneous cartels are relevant for decentralized firms.

${ }^{22} 2 \pi_{i}^{c M} \leq \pi_{i}^{c U}$, since divisions inside a firm do not cooperate.

${ }^{23}$ We maintain theses values for all the graphical representations in this article.

${ }^{24}$ The $U_{s e q}$ strategy does not appear as it is always dominated by the $M c$ strategy.
} 


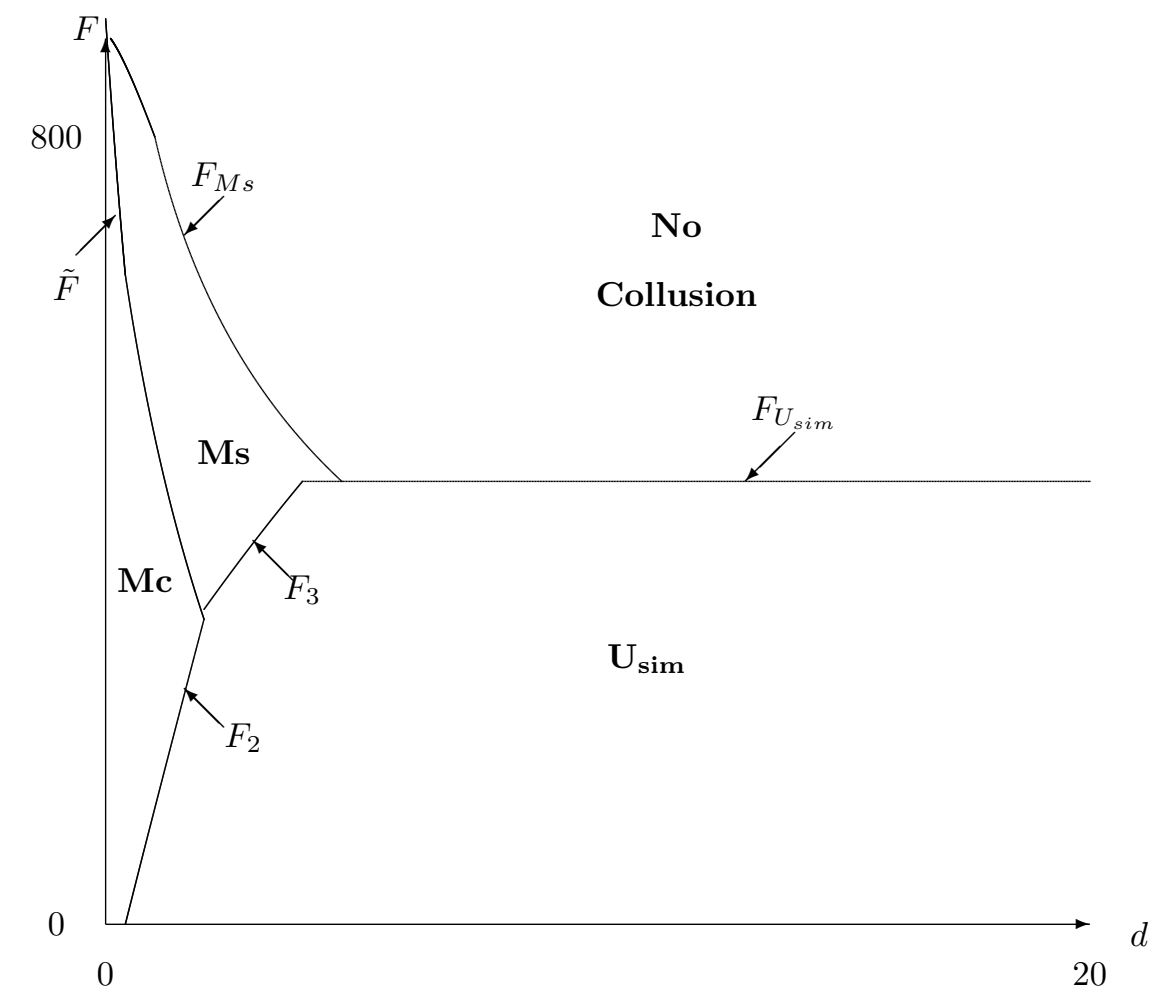

Figure 1: Equilibrium organizational structures without LP

\section{Leniency programs}

Decentralization leads to hide proofs of the second cartel and helps to sustain collusion. We analyze if the leniency programs can induce firms to self-report the hidden evidence and thus defeat the decentralization strategy. In this section, we introduce simple LP without Amnesty Plus possibility. Scenarios S and L are successively studied.

\subsection{Scenario $\mathrm{S}$}

Under centralized organization firms can apply for leniency only at stage (2) (see the paragraph "chronology of each period" above). At stage (8) both cartels are detected and firms can no longer apply for leniency. Decentralized firms could potentially apply for leniency at stage (8) but they never find it advantageous since hard evidences disappear at the end of the period. ${ }^{25}$ The antitrust authority cannot incentivize firms to selfreport hidden evidence with simple LP. Stage (2) is the only time firms can apply for leniency if they deviate from the agreement during stage (1). For some parameters values firms can deviate from the agreement and simultaneously apply for leniency to prevent them for being fined. But in this case firms expect that cartel is not sustainable and do not collude. The only impact of the LP is to modify sustainability conditions by

\footnotetext{
${ }^{25}$ We do not analyze the case in which a firm applies for leniency only because the other firm applies too. As for the organizational choice we suppose that firms are able to coordinate themselves on the best equilibrium.
} 
increasing deviation profit. ${ }^{26}$

The presence of the LP does not alter the values of $\Pi_{i}^{U_{s i m}}, \widetilde{\Pi}_{i}, \Pi_{i}^{U_{s e q}}, \Pi_{i}^{M s}$ and $\Pi_{i}^{M c}$. Nonetheless, sustainability conditions are modified since deviation profits are increased. The new threshold values are indicated below:

$$
\begin{array}{ccc}
F_{U_{s i m}}=\frac{2 \delta(1-\rho)^{2}-1}{2 \rho(2-\rho)} \pi_{i}^{c U} & \widetilde{F}=\frac{2 \delta(1-\rho)-1}{\rho} \widetilde{\pi}_{i}^{c} & F_{U_{s e q}}=\frac{3 \delta-2 \delta \rho-2 \delta^{2}(1-\rho)^{2}-1}{(1-\delta+2 \delta \rho) \rho} \widetilde{\pi}_{i}^{c} \\
F_{M s}=\frac{2 \delta(1-\rho)^{2}-1}{\rho} \pi_{i}^{c M} & F_{M c}=\frac{[1-\delta(1-\rho)]\left[2 \delta(1-\rho)^{2}-1\right] \pi_{i}^{c M}+\delta(1-\rho) \rho \widetilde{\pi}_{i}^{c}}{\left[1-\delta(1-\rho)^{2}\right] \rho} &
\end{array}
$$

Expressions of $F_{2}$ and $F_{3}$ are the same as before since expected profit associated to different collusive strategies are unchanged. The LP modify the border lines in the Figure 1. The Figure 2 serves to illustrate these modifications (we also plot on the graph the border lines of benchmark case values without LP with dots for comparison).

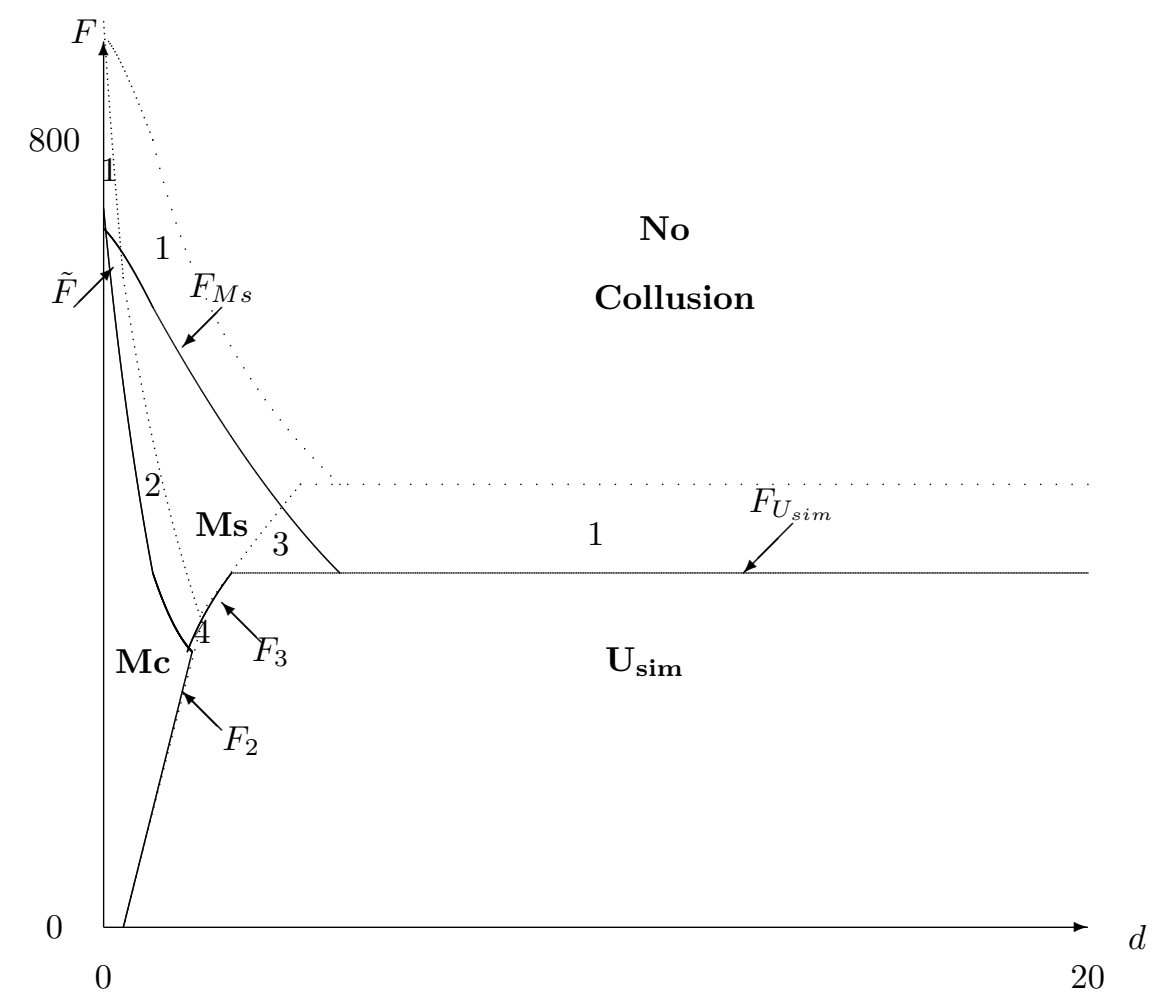

Figure 2: Impact of the LP in scenario S

All the border lines move downward: collusion is more difficult to sustain whatever organizational structure is and completely disappears in zones 1 . In zone 2 collusion is not completely deterred but the introduction of the LP prevents collusion to be pursued in the second market after the detection in the other market: there is a switch from the $M c$ strategy to the $M s$ one. The LP have pro-competitive effects, but firms never apply on the equilibrium path and still can hide evidence by decentralising price choices.

\footnotetext{
${ }^{26}$ The LP have not impact at all if we assume that firms can not be fined during deviation period (this point was noted by Motta and Polo, 2003, and underlined in Spagnolo, 2008).
} 
The LP can also impact the firms' internal organization. In zone 3 collusion under centralized organization is no longer sustainable and firms switch to the M-form organization causing collusive price to decrease. In the small zone 4 the LP have an anticompetitive effect since firms adopt a more centralized structure and collusive prices are increased. In this zone the $M c$ strategy is no longer sustainable and firms prefer the $U_{\text {sim }}$ strategy to the $M s$ one because prices are higher. In this zone the LP shorten collusion by destabilizing the $M c$ strategy but collusive prices are increased.

Proposition 2 In scenario S, LP make collusion more difficult to sustain whatever the organizational structure is. They can modify the choice of organizational design in one or other direction.

\subsection{Scenario L}

Firms can now apply for leniency at stage (6). It makes no difference for decentralized firms since we consider perfect compartmentalization inside the firm: if they did not have interest to apply for leniency at stage (8) they do not have interest as well to apply at stage (6). Nonetheless, it is a real opportunity for the firms playing the $U_{\text {sim }}$ strategy because the conviction of the second cartel is inescapable, so they will apply for leniency at stage (6) if the first cartel has been detected. This yields to a reduction of expected fine from $2 F$ to $\frac{3}{2} F$. We obtain the following results:

$$
\Pi_{i}^{U_{s i m}}=\frac{\pi_{i}^{c U}-(3-\rho) \rho F}{1-\delta(1-\rho)^{2}} \quad ; \quad F_{U_{s i m}}=\frac{2 \delta(1-\rho)^{2}-1}{(3-\rho) \rho} \pi_{i}^{c U}
$$

The expressions of $\widetilde{\Pi}_{i}, \Pi_{i}^{U_{s e q}}, \Pi_{i}^{M s}$ et $\Pi_{i}^{M c}$ are unchanged from sections 3 and 4.1. The border lines of sustainability $\widetilde{F}, F_{U_{s e q}}, F_{M s}$ et $F_{M c}$ are the same as in section 4.1 , but the expressions of $F_{2}$ et $F_{3}$ are modified since the value of $\Pi_{i}^{U_{\text {sim }}}$ is altered:

$$
F_{2}=\frac{[1-\delta(1-\rho)]\left(\frac{\pi_{i}^{c U}}{2}-\pi_{i}^{c M}\right)-\delta(1-\rho) \rho \widetilde{\pi}_{i}^{c}}{\frac{1}{2}(1-\delta-\delta \rho)(1-\rho) \rho} \quad ; \quad F_{3}=\frac{\frac{\pi_{i}^{c U}}{2}-\pi_{i}^{c M}}{\frac{1}{2}(1-\rho) \rho}
$$

Figure 3 illustrates this point by plotting the new equilibrium structures (we also plot on the graph the border lines of the benchmark case without LP with dots for comparison).

For low values of $d$, we obtain the usual effects of the LP. In zones 1 collusion is deterred by the presence of the LP whereas in zone 2 cartels are shorter-lasting and firms switch from the $M c$ strategy to the $M s$ one. LP have pro-competitive effects if firms adopt decentralized organization.

But LP can also have anti-competitive effects if firms choose centralized organization. The $U_{\text {sim }}$ strategy strongly benefits from scenario L as LP decrease the expected fine. In zone 3 collusion is sustainable only if LP are introduced. Grant total immunity for the second cartel if it is reported at stage (6) is too generous.

The LP can also modify the choice of organizational structure of the firms. In zone 4 firms adopt a centralized organization and can avoid to be fined for the second cartel with probability 0.5 . There is less 
need to compartmentalize activities even if it allows firms to avoid the second fine with certainty. ${ }^{27}$ The LP favor the adoption of centralized organization not because decentralized strategies are destabilized, but because LP protect partially firms using $U_{\text {sim }}$ strategy against the risk of double fine. The firms still can hide evidence by adopting M-form, but it is not an actual necessity because by self-reporting the second cartel they can avoid (with probability 0.5 ) the second fine.

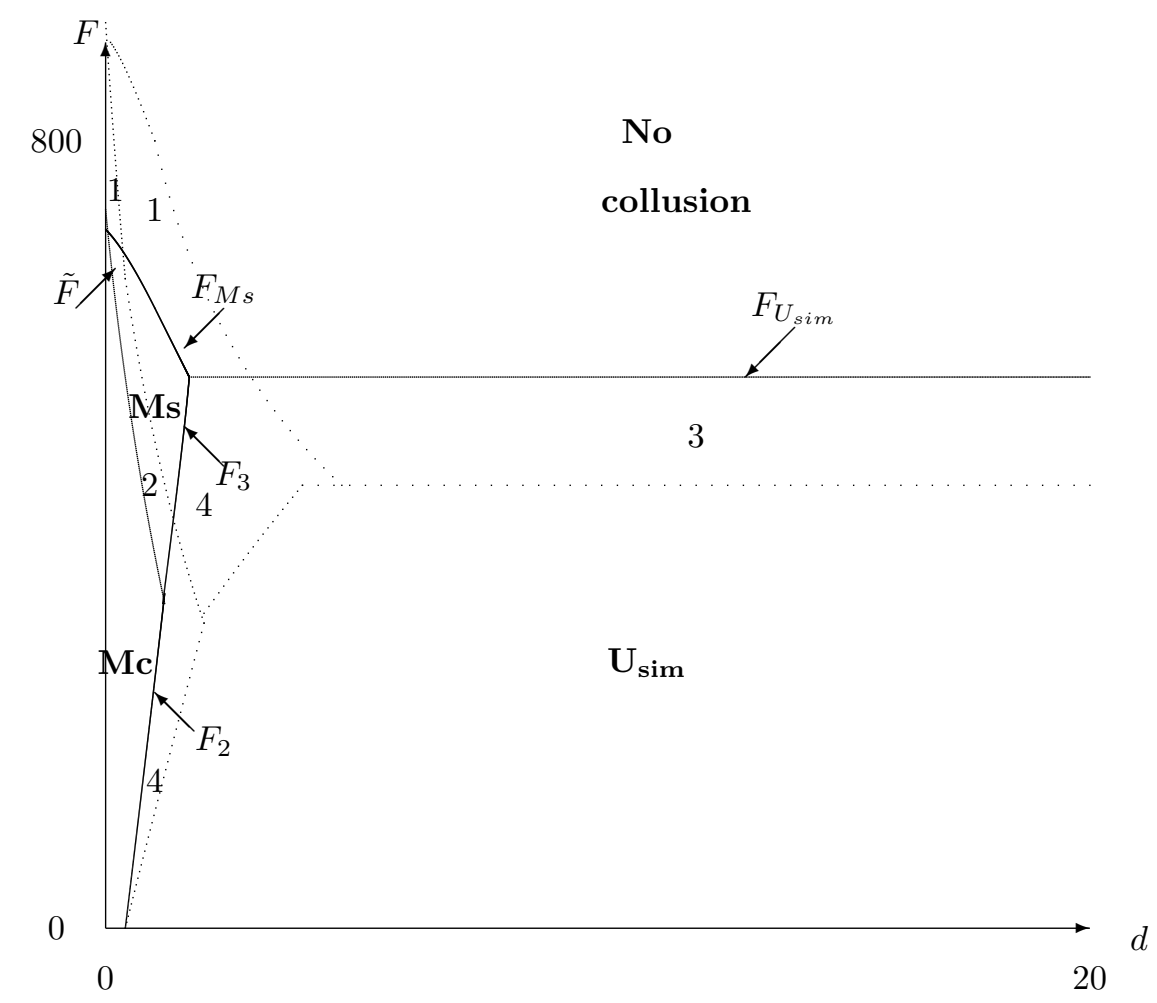

Figure 3: Impact of the LP in scenario L.

Comparison with scenario S: It seems to be socially better to prohibit firms to apply for leniency for the second cartel after the detection of the first one since scenario L has pro-collusive effects. As we noted in section 2, granting total immunity for the second cartel at stage (6) if firms self-report is not optimal. In scenario $\mathrm{L}$ with $\mu_{2}=1$ et $\mu_{3}=0$, it is optimal not allow firms to apply for leniency at this stage.

However some positive effects of scenario L could occur if we introduced for instance the administrative costs of investigations or costs of actions in the courts. These costs could be decreased if firms cooperated with the antitrust authority during investigations and this could yield to an increased probability of condemnation (this effect is neutralized in our paper as we set $\mu_{1}=1$ ) or an increased probability to discover the second cartel (this effect is neutralized in our paper since we assume that $\mu_{2}=1$, but this assumption will be weakened in the section 6$)$.

Proposition 3 Allowing leniency applications during the investigation process extends opportunities for cen-

\footnotetext{
${ }^{27}$ More precisely with probability $1-\rho$, firms continuing to pay a double fine if antitrust authority simultaneously detects the two cartels.
} 
tralized firms to make collusive agreements and may drive firms to adopt a more centralized organization.

Incentives of competition authority: We suggest that it is not optimal to allow for leniency at stage (6). Harrington (2011) notes that the choice of antitrust authorities may depart from the social optimum if their incentives are badly conceived. In his model antitrust authority seeks to maximize the number of condemnations and not minimize the number of existing cartels. ${ }^{28}$ The antitrust authority can choose not to systematically prosecute detected cartels in order to decrease the deterrent effect and to increase the number of cartels. In this case it condemns a lower proportion of a higher number of cartels which can imply a higher number of condemnations. In our model if the presence of LP implies a switch from the $M s$ strategy to the $U_{\text {sim }}$ one then social surplus is decreased since the collusion is the same length but with higher prices. However the antitrust authority can enjoy this switch because the number of condemnations is increased. The antitrust authority can fine twice firms under the $U_{\text {sim }}$ strategy which is not the case under the other strategy under which the second cartel is also shut down but the antitrust authority does not own hard evidences of this second cartel. The same problem can be found if the antitrust authority seeks to maximize the global amount of fines. Fines are higher when firms play the $U_{\text {sim }}$ strategy compared to the $M s$ one. The antitrust authority weakens deterrence by introducing the LP in order to induce firms to make less of an effort to hide hard evidences rather than to increase the numbers of cartels. Furthermore if zone 3 is larger than zones 1 and 2 we obtain the same effect as in Harrington (2011): the antitrust authority weakens deterrence by introducing the LP in order to increase the numbers of cartels. Consequently, if their incentives are badly conceived, antitrust authorities can allow for leniency at stage (6) even if it is not socially optimal.

\section{Amnesty Plus programs}

As previously mentioned simple LP do not induce CEO to search and report hard evidence hidden by firms with decentralization when $\mu_{3}=0$. In this section, we prove that Amnesty Plus programs [AP] can sometimes do this task. These US programs consist of reduced fines for already convinced firm if it reports an other undetected cartel to the antitrust authority. Scenarios S+ and L+ are successively studied.

\subsection{Scenario $\mathrm{S}+$}

The introduction of the AP does not change collusive strategies of centralized firms and hence $\Pi_{i}^{U_{s i m}}, \widetilde{\Pi}_{i}$ and $\Pi_{i}^{U_{s e q}}$ are unchanged. At stage (8) firms are unable to apply for leniency since the two cartels have been detected.

Nonetheless the AP can alter collusive strategies for decentralized firms. In order leniency be applied, either managers desire to pass on hard evidence to their CEO, or in the opposite case CEO can obtain theses proofs by conducting internal audit. To simplify the analysis, we assume that the cost of an audit is equal

\footnotetext{
${ }^{28}$ This distinction between maximizing arrests and minimizing crimes is also highlighted in the literature concerning deterrence (Persico, 2002).
} 
to zero $(k=0) \cdot{ }^{29}$

If managers believe that audit will be unsuccessful $(\sigma=0)$ they do not have any incentive to reveal the information about the second cartel. The objective of each manager is to maximize the profit of his own division which is not changed by the AP. Furthermore when they establish the collusive agreement, managers decide not to use these AP since they can not increase their own profit but only decrease the profit of the second-place firm if the firms apply for leniency with the AP. ${ }^{30}$ Consequently the AP have no impact if we consider $\sigma=0$.

If $\sigma>0$ the CEO may wish to denounce the second cartel (even if the probability of detection by serendipity is equal to 0) to profit from a reduced fine concerning the first cartel. If firms adopt the $M s$ strategy the second cartel will be dissolved and hence firms have an incentive to denounce it to the antitrust authority to benefit from reduced fine for the first cartel. When they dispose of the relevant information, applying for the AP is a dominant strategy for the CEO and managers have an interest to pass on evidences because they prefer their own CEO apply for leniency than the CEO of the other firm. If it is the case their division will not be fined but the other will pay a fine $F$. Consequently the AP encourage firms playing $M s$ strategy to automatically use of leniency for the second cartel (if $\sigma>0$ ). Each firm is individually better of applying the AP but it is not the collectively best action (if $\tau>0$ ): the introduction of the AP leads to a prisoner dilemma situation. The AP allow antitrust authorities to induce CEO to become alternative to antitrust authorities and to provide evidences hidden by decentralization.

We obtain the following expressions concerning the $M s$ strategy:

$$
\Pi_{i}^{M s}=\frac{\pi_{i}^{c M}-\left[1+\frac{1}{2}(1-\rho) \tau\right] \rho F}{1-\delta(1-\rho)^{2}} \quad ; \quad F_{M s}=\frac{2 \delta(1-\rho)^{2}-1}{\left[1+\frac{1}{2}(1-\rho) \tau\right] \rho} \pi_{i}^{c M} \quad \text { and } \quad F_{3}=\frac{\frac{\pi_{i}^{c U}}{2}-\pi_{i}^{c M}}{\left(1-\frac{1}{2} \tau\right)(1-\rho) \rho}
$$

We now turn to the $M c$ strategy. If a CEO believes that the other will apply for leniency then he will automatically use the leniency provided that information is available. If the other firm does not apply for leniency, the CEO of the first firm has to decide between applying for leniency (with an immediate decrease in fine of $(1-\tau) F)$ or continuing to collude in the second market (which yields to an expected profit $\widetilde{\Pi}_{i}$ ). A CEO will apply for leniency if:

$$
(1-\tau) F \geq \widetilde{\Pi}_{i} \Leftrightarrow F \geq \frac{\widetilde{\pi}_{i}^{c}}{[1-\delta(1-\rho)](1-\tau)+\rho} \equiv F_{\text {report }}
$$

If a CEO does not want to apply for leniency then managers of each division has no reason to do so because they can continue to collude if they don't cheat and obtain $\widetilde{\Pi}_{i}$ whereas they obtain zero if they reveal the cartel.

If a CEO wants to apply for leniency then a manager has an interest to cooperate if he believes that the other manager is doing so. If he believes that the manager of the other division is not willing to cooperate, then the profit of his own division is $0-\frac{1}{2} \sigma F$ if he cooperates and $(1-\sigma)^{2} \widetilde{\Pi}_{i}-\sigma(1-\sigma) F-\frac{1}{2} \sigma^{2} F$ in the

${ }^{29}$ The case $k>0$ will be analyzed in the section 6 .

${ }^{30}$ We do not analyze the case in which a firm applies for leniency only because the other firm applies too. 
other case. Consequently a manager desires to pass on hard evidence to his CEO if:

$$
(1-\sigma)^{2} \widetilde{\Pi}_{i}-\sigma(1-\sigma) F-\frac{1}{2} \sigma^{2} F \geq 0-\frac{1}{2} \sigma F \Leftrightarrow \widetilde{\Pi}_{i} \geq \frac{1}{2} \frac{\sigma}{1-\sigma} F
$$

If $\sigma>\frac{2-2 \tau}{3-2 \tau}$, then $(1-\tau) F \geq \widetilde{\Pi}_{i}$ implies $\frac{1}{2} \frac{\sigma}{1-\sigma} F \geq \widetilde{\Pi}_{i}$. Managers cooperate with the CEO if there is internal audit. The audits' probability of success is high. So if a manager is successful in concealing information from his CEO then there is a major risk that the other firm applies for leniency because its audit was a success. If the success probability of the audit is low $\left(\sigma<\frac{2-2 \tau}{3-2 \tau}\right)$ then managers prefer not to cooperate and try to continue the second cartel despite their CEO. In this section we assume that: $\sigma>\frac{2-2 \tau}{3-2 \tau}$. ${ }^{31}$ So managers always cooperate if their CEO wish to apply for leniency.

If $F<F_{\text {report }}$ firms can commit not to apply for leniency at stage (8) if they play the $M c$ strategy. $\Pi_{i}^{M c}$ and $F_{2}$ are unchanged from the benchmark case without LP and $F_{M c}$ is the same as in the section 4.1. If $F \geq F_{\text {report }}$ firms apply for leniency. Since the managers cooperate with their CEO the second cartel is always denounced after the detection of the first and so the $M c$ strategy is no longer viable and decentralized firms switch to the $M s$ one.

Without AP firms have not any incentive to reveal the existence of the second cartel after the detection of the first. The introduction of the AP modifies the strategy of the firms which can use the LP on the equilibrium path, as they always do when they play the $M s$ strategy. A firm which is the first to reveal the second cartel obtains total immunity from fines for this second cartel and a reduced fine of $(1-\tau) F$ for the first one. Applying for leniency is a dominant strategy for firms playing the $M s$ strategy. But it is not the collectively best action since the other firm will be condemned for the second cartel whereas it would have remained undiscovered by serendipity without AP. Firms face a prisoner dilemma situation and firms are now encouraged to denounce one another.

The $M s$ border line moves downward hence the introduction of the AP prevents collusion to be adopted for some values of $d$ and $F$ whereas the simple LP were not enough to deter collusion. The $M c$ strategy is also affected by the introduction of the AP. After the detection of the first cartel firms must choose (if $F<\widetilde{F}$ ) between maintaining collusion in the second market or obtaining reduction of fine for the first cartel by applying for leniency. If the reduction of fine is high (low value of $\tau$ ) it is difficult to sustain the $M c$ strategy. In the area bounded by $F<\widetilde{F}$ and $F \geq F_{\text {report }}$ the $M c$ strategy is no longer sustainable under the presence of the AP. The CEO wants to reveal the information about the second cartel to benefit from the AP and, as $\sigma$ is high, manager always provides the information. Decentralized firms can only play the $M s$ strategy. In the area bounded by $F<\widetilde{F}$ and $F>F_{M s}, M s$ strategy is no sustainable. Firms switch to the $U_{s e q}$ strategy which is the only sustainable strategy. The AP can not destabilize this type of collusion since at stage (8) firms can not reveal a cartel which does not yet exist. Overall the AP make collusion more difficult to sustain for decentralized firms. Then the AP have pro-competitive effects.

The AP may also impact the choice of organizational structure. The border line $F_{3}$ moves to the left (profit with the $U_{\text {sim }}$ strategy are unchanged): the AP favor centralization structure. Compartmentalization

\footnotetext{
${ }^{31}$ The opposite case will be analyzed in section 6 .
} 
no longer allows firms to avoid the second fine with certainty but only with probability 0.5. Decentralized structure may allow firms to obtain a reduction for the first cartel (with the AP). However the first effect dominates the second one and firms favor the adoption of centralized structure. Collusive prices are increased when firms switch to centralization thus AP can have anti-competitive effect.

Proposition 4 The introduction of the AP reduces opportunities for decentralized firms to make collusive agreements and may drive firms to adopt a more centralized organization.

The figure 4 serves to illustrate the equilibria for $\tau=0.5$ (we also plot the border lines obtained without LP with dots for comparison).

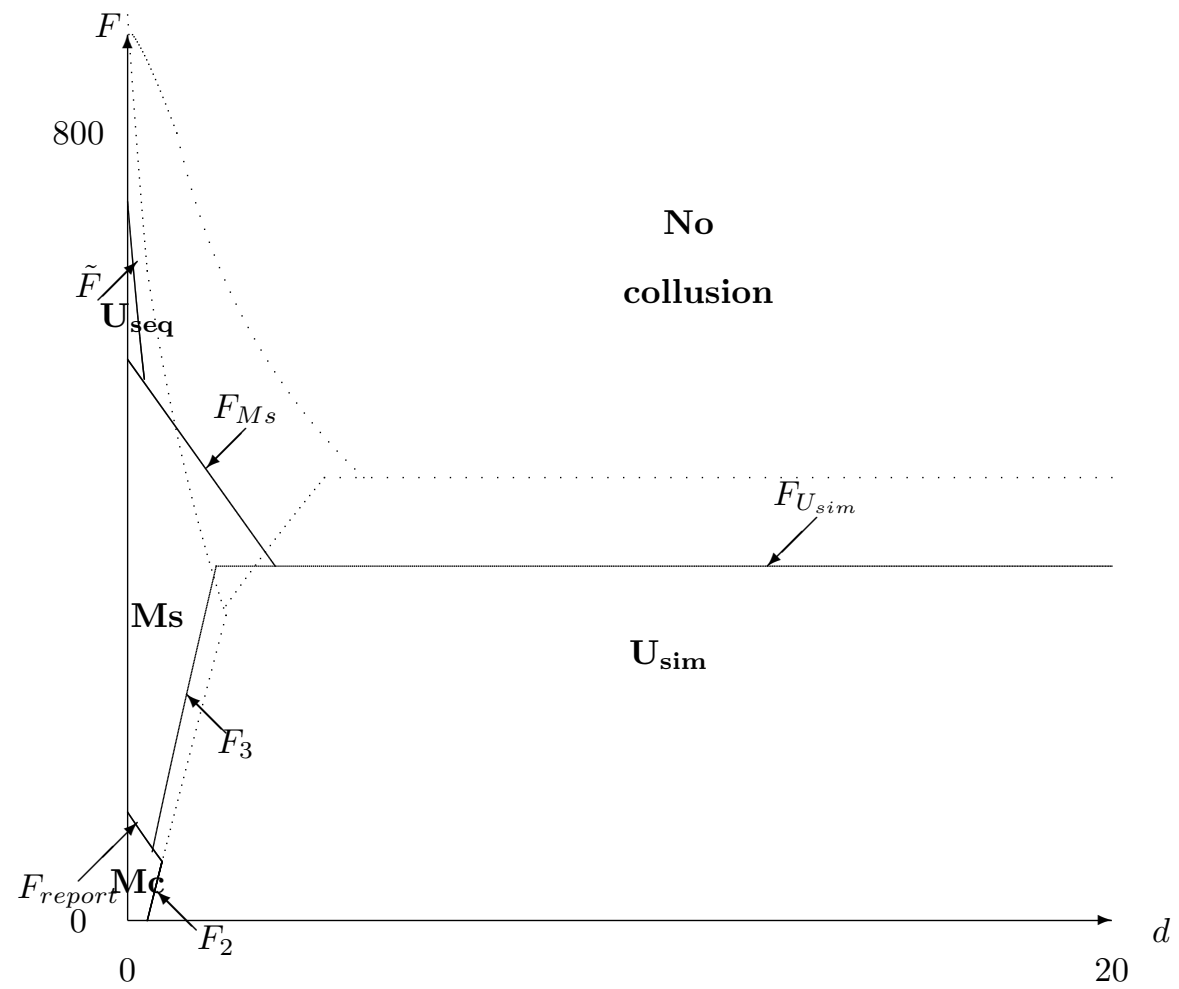

Figure 4: Equilibria obtained with scenario S+.

\subsection{Scenario L+}

Effects of the AP on the pay-offs under strategies $M s$ and $M c$ are the same to those of $\mathrm{S}+$ since $\mu_{3}=0$. Consequently the expressions $\Pi_{i}^{M s}, \Pi_{i}^{M c}, F_{M s}, F_{M c}$ and $F_{\text {report }}$ remain unchanged from the above subsection.

Centralized firms always apply for leniency at stage (6) as in scenario L, the introduction of the AP strengthens interest in this application. We obtain the following expressions:

$$
\Pi_{i}^{U_{s i m}}=\frac{\pi_{i}^{c U}-(2+\tau-\rho \tau) \rho F}{1-\delta(1-\rho)^{2}} \quad F_{U_{s i m}}=\frac{2 \delta(1-\rho)^{2}-1}{(2+\tau-\rho \tau) \rho} \pi_{i}^{c U} \quad F_{2}=\frac{[1-\delta(1-\rho)]\left(\frac{\pi_{i}^{c U}}{2}-\pi_{i}^{c M}\right)-\delta(1-\rho) \rho \tilde{\pi}_{i}^{c}}{\left\{\frac{1}{2}[1-\delta(1-\rho)] \tau-\delta \rho\right\}(1-\rho) \rho}
$$


The $M s$ strategy is always dominated by the $U_{\text {sim }}$ one. After the first cartel is detected, firms can now apply for leniency for the second cartel with the $U_{\text {sim }}$ strategy and they obtain the same expected profits as in the $M s$ strategy. But before the first cartel is detected the $U_{\text {sim }}$ strategy yields higher profit since collusive prices are higher.

Proposition 5 If leniency can be applied during the investigation process then the AP lead to higher expected profits under the $U_{\text {sim }}$ strategy and may drive firms to adopt a more centralized organization.

The figure 5 (we choose $\tau=0.5$ ) serves to illustrate the results (border lines obtained without LP are plotted with dots for comparison).

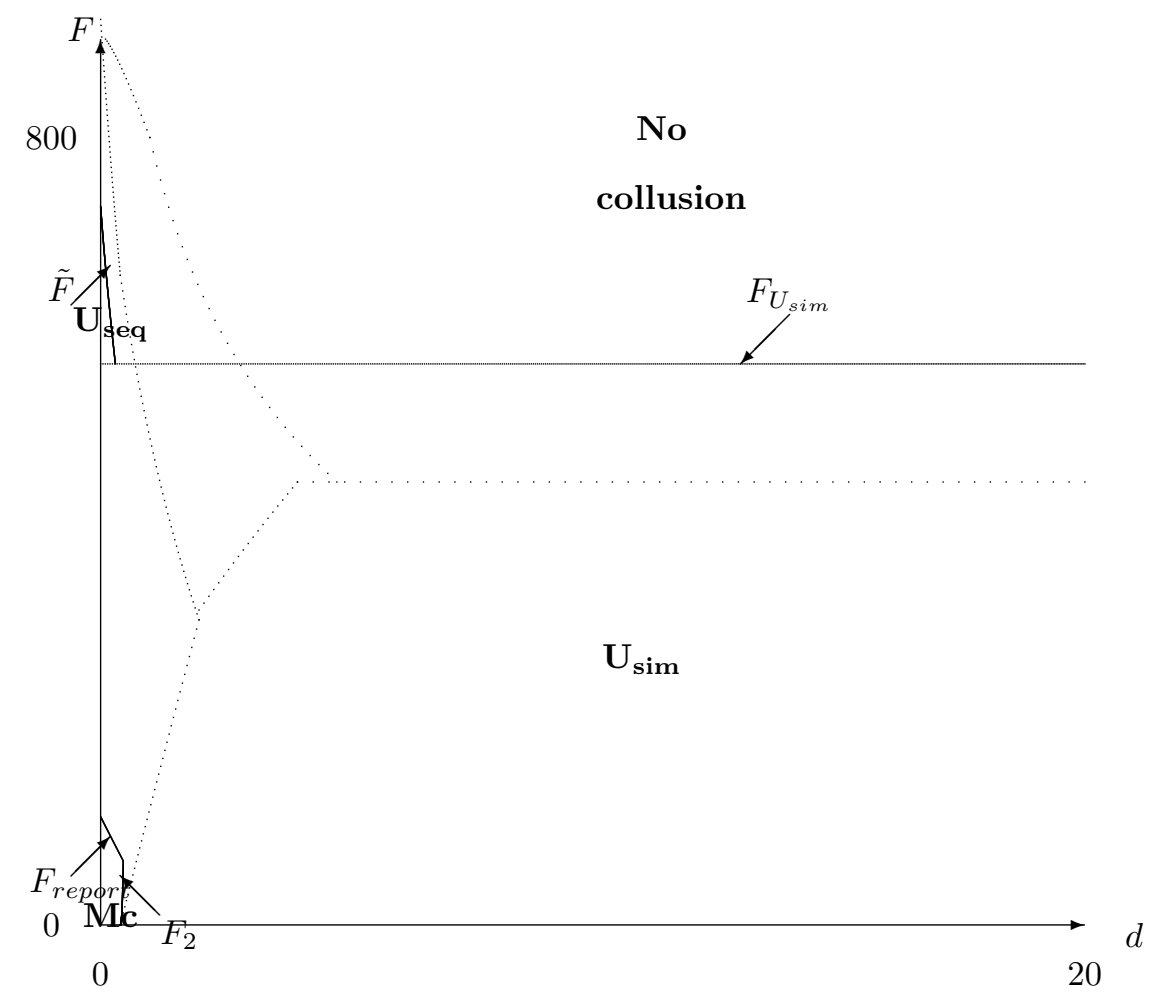

Figure 5: Equilibria obtained with scenario L+.

The $M c$ strategy is destabilised by the temptation of the CEO to reveal the existence of the second cartel so as to benefit from the AP, it is no longer sustainable if $F>F_{\text {report }}$. The border line $F_{2}$ moves to the left since the expected profits under the $U_{\text {sim }}$ strategy are higher. Then the $M c$ area is very small whereas the $U_{\text {sim }}$ one becomes very large. The $U_{\text {seq }}$ strategy is selected for a very small range of parameters. The border line $F_{U_{s i m}}$ moves upward: the AP expand the anti-competitive effect of LP in scenario L and may help centralized firms to sustain collusive outcomes.

Comparison with scenario S+: Allowing leniency applications during the investigation process produces the same qualitative effects with or without the AP. The expected profits under the $U_{\text {sim }}$ strategy are higher 
and this favors the adoption of a more centralized structure. It appears again that it is socially better to prohibit firms to apply for leniency during the investigation process (at stage 6). But once the investigation has been completed the antitrust authority should permit firms to apply again for leniency (in stage 8) in order to destabilize collusive agreements obtained with decentralized firms.

\subsection{Comparison with Lefouili and Roux (2012)}

Our main results are consistent with Lefouili and Roux (2012) [LR]. Firstly the presence of the AP as well as a higher fine reduction (smaller value of $\tau$ ) decrease the sustainability of the second cartel once the first one has been detected. In our paper this results in reduced area where the $M c$ strategy is sustainable. This is the pro-competitive effect of the AP. Secondly we can observe in our paper a pro-collusive effect of the AP for centralized firms playing the $U_{\text {sim }}$ strategy in scenario $L+$. Consequently we reach the same double effect as LR.

Our results may differ from LR in the detail of the analysis. The main discrepancy is the impact of the AP on the $M s$ strategy. In our paper we assume that the antitrust authority can detect active cartels (including during the deviation period) but past offence can no longer be detected once firms have reverted to competitive pricing, this is not the case in LR. So in their paper firms always apply for leniency when the cartel is broken even in absence of AP. This differs from our results since the firms playing the $M s$ strategy do not reveal the existence of the second cartel when it is broken if the simple LP are proposed. The AP lead firms playing the $M s$ strategy to reveal the information of the second cartel, and the $M s$ strategy can be no longer sustainable. Under the LR assumptions this second cartel would be revealed even if the AP were not proposed and in the opposite case, the $M s$ strategy would yield higher profit and would be easier to sustain. The results of our proposition 4 would be the opposite under the LR assumptions: the introduction of the $\mathrm{AP}$ would drive firms to adopt a more decentralized organization (moving $F_{3}$ to the right) in scenario $\mathrm{S}+$. For the same reasons, the AP may yield firms to switch from the $M s$ strategy to the $U_{\text {seq }}$ one in our model whereas in LR firms could switch from a sequential collusion to a simultaneous one. These opposite results can be explained by the impact of the AP on the $M s$ strategy which is inverted between the two papers.

The second difference is that in LR firms can make collusive agreements in only one market and never collude in the other market. This equilibrium never appears in our paper. Two reasons explain this equilibrium discrepancy. First the different assumption highlighted above implies that, even with the simple LP, firms always reveal the second cartel in LR when they play equivalent strategy to the $M s$ one. So the expected fine is higher in LR when firms collude in the two markets. Second LR assume that after the first cartel is detected the antitrust authority strengthens the second cartel monitoring by increasing the detection probability from $\rho$ to $\bar{\rho} .{ }^{32}$ So the expected profit of colluding on the second market after the conviction of a first cartel is lower in LR. In LR, the introduction of the AP may yield firms to switch from a one-market

\footnotetext{
${ }^{32}$ The justification of this assumption by LR reflects our idea that once the authority has successfully dealt with one cartel there is a clear likelihood that others may be discovered. The modelling used in the two papers is different since we assume $\mu_{2}=1$ whereas LR assume an increased probability of detection. Without this modification of $\rho$ the $U_{s e q}$ strategy always dominates the strategy whereby firms collude in only one market and stop colluding once firms are fined.
} 
collusive agreement to a $M s$ strategy. This anticompetitive effect is not existent in our paper.

Last but not least, LR do not distinguish between the $M s$ and $U_{\text {sim }}$ strategies. In our model the AP may lead to anticompetitive effect by rising price since firms may switch from the $M s$ strategy to the $U_{\text {sim }}$ one. This effect is not present in LR and is one of the contributions of our paper.

\section{Extensions}

When we consider $\mu_{2}=1, \mu_{3}=0, k=0$ and a high value of $\sigma$ the results of our study are quite clear. In scenario S, LP make collusion more difficult to sustain whatever the organizational structure is. They can modify the choice of organizational design in one or other direction. If firms switch from a decentralized organization to a centralized one, collusion is shortened but collusive prices are increased. The introduction of the AP (Scenario S+) reduces opportunities for decentralized firms to make collusive agreements (without any modification for centralized firms) and may drive firms to adopt a more centralized organization. Allowing leniency applications during the investigation process (Scenarios L and L+) extends opportunities for centralized firms to make cartels and may drive firms to adopt a more centralized organization.

In this section, we highlight the impacts of $\mu_{2}, \mu_{3}, k$ and $\sigma$. We also analyze how the results vary with different timing of the game.

\subsection{Imperfect compartmentalization $\left(\mu_{3}>0\right)$}

We now assume that under decentralization the collusive agreements are imperfectly insulated: $\mu_{3}>0$. DJ already studied the case $\mu_{3}>0$ without LP. The expected fine for firms playing the $M s$ strategy is increased by $(1-\rho) \rho \mu_{3} F$ for each period. The expected profit under the $M c$ strategy is decreased since the probability to continue collusion on the second market after the detection of the first is decreased. Thus compartmentalization of activities is less attractive. The border lines moved to the left and a new region in the graph was created where firms chose the $U_{\text {seq }}$ structure. An increase in $\mu_{3}$ provided stronger incentives to choose the U-form design (proposition 7 of DJ).

Scenarios S and S+: Qualitative results obtained with scenario $\mathrm{S}$ are not altered considering $\mu_{3}>0$ since decentralized firms never choose to apply for leniency on the equilibrium path. The only effect of the LP is to move all the border lines to the bottom as in section 4.1.

Under scenario $\mathrm{S}+$, the assumption $\mu_{3}>0$ brings with it the possibility that the second cartel is discovered before CEO reveals it. In this case CEO may not benefit from leniency and the AP at stage (8). The expected profit of the firms playing the $M s$ strategy is decreased as $\mu_{3}$ is increased. The behavior of the firms playing the $M c$ strategy is not affected by a modification of $\mu_{3}$. Once the first cartel has been discovered the antitrust authority finds cogent evidence of the second one with probability $\mu_{3}$ and nothing can be done. If the second cartel is not detected then firms have the same incentives to apply for leniency as in the $\mu_{3}=0$ case. The 
incentives to apply for leniency are not affected by the value of $\mu_{3}$. But the number of leniency applications is, because firms cannot apply for leniency if the second cartel is detected by serendipity in stage 7 .

The expected profit of the firms playing the $M c$ strategy is decreased as $\mu_{3}$ is increased. An increased value of $\mu_{3}$ moves the border lines bounding the regions in which $M c$ and $M s$ are sustainable downward whereas $F_{2}$ and $F_{3}$ move to the left. Proposition 4 remains valid. ${ }^{33}$

Scenarios $\mathbf{L}$ and $\mathbf{L}+$ : We obtain further results under scenario L. Decentralized firms playing the $M s$ strategy always apply for leniency once the first cartel has been detected. ${ }^{34}$ But in this case this strategy is dominated by the $U_{\text {sim }}$ one and the $M s$ strategy is no longer an equilibrium strategy. If firms wish to play the $M c$ strategy they must have no incentive to reveal the second cartel once the first one has been detected. If a manager believes that the other firm will not apply for leniency, then he expects a division pay-off equal to 0 if he applies for leniency, and $\left(1-\mu_{3}\right) \widetilde{\Pi}_{i}-\mu_{3} F$ otherwise. He applies for leniency iff:

$$
\left(1-\mu_{3}\right) \widetilde{\Pi}_{i}-\mu_{3} F<0 \Leftrightarrow \frac{\left(1-\mu_{3}\right) \widetilde{\pi}_{i}^{c}}{\rho\left(1-\mu_{3}\right)+[1-\delta(1-\rho)] \mu_{3}}<F \Leftrightarrow \frac{\widetilde{\pi}_{i}^{c}-\rho F}{[1-\delta(1-\rho)] F+\widetilde{\pi}_{i}^{c}-\rho F}<\mu_{3}
$$

An increased value of $\mu_{3}$ decreases the expected pay-off of the $M c$ strategy and can render it unsustainable. LP are ineffective against decentralized firms when $\mu_{3}=0$. They can become very effective when $\mu_{3}>0$. Effort to increase $\mu_{3}$ and introduction of LP in scenario L are complementary tools for the antitrust authority to fight collusion by decentralized firms. Proposition 3 remains valid and is indeed strengthened. On the other hand we can no longer affirm that it is socially better to prohibit firms to apply for leniency in stage (6). Allowing firms to apply at stage (6) has pro-competitive effect if firms are decentralized and pro-collusive effect if they are centralized. We must qualify our recommendation. Leniency in stage 6 would not be proposed if the two goods are near substitutes because pro-collusive effects appear since firms always choose centralization. In the opposite, if goods are poor substitutes and if $F$ is low, allowing leniency in stage 6 can destabilize the $M c$ strategy and induce firms to switch to the $U_{\text {sim }}$ one. Collusion is shortened but collusive prices slightly increase. If $d$ is very low, the first effect dominates the second one and expected social welfare increases when leniency is allowed in stage 6 . If $d$ is low and $F$ is relatively high, allowing leniency in stage 6 induces firms to switch from the $M s$ strategy to $U_{\text {seq }}$ one. Collusion lasts longer but collusive prices are lower (if $d>0$ ). If $d$ is low and $F$ is intermediate, firms switch from the $M s$ to the $U_{s i m}$ strategy when they are allowed to apply for leniency in stage 6 . In this case welfare decreases as collusive prices are higher and duration of collusion is unchanged.

Under scenario L + , assuming $\mu_{3}>0$ strengthens the incentives of decentralized firms to apply for leniency in stage 6 and decreases the region where $M c$ is sustainable. Even if $M c$ is sustainable, the expected profits are decreased and the border line $F_{2}$ moves to the left. Amnesty plus shortens collusion if firms switch from $M c$ to $U_{\text {sim }}$. In the other cases, amnesty plus may decrease social welfare by making collusion for centralized firms easier. Our recommendation is to not combine amnesty plus and L timing if $d$ is high, because in this case firms play the $U_{\text {sim }}$ strategy and amnesty plus favors collusion.

\footnotetext{
${ }^{33}$ The proposition 7 of DJ remains valid as well.

${ }^{34}$ This results to a modification of the expected fine from $\mu_{3} F$ to 0 if the other firms does not apply for leniency and from $F$ to $\frac{1}{2} F$ in the opposite case.
} 


\subsection{Imperfect detection in the centralization case $\left(\mu_{2}<1\right)$}

We now assume that when the antitrust authority investigates the first cartel then centralized firms face a risk of detection for the second agreement lower than one: $\mu_{2}<1 .^{35}$ In this case an other strategy may appear: centralized firms can simultaneously collude in the two markets and when a cartel has been successfully detected in only one market firms can continue to collude in the other market provided that it has not been detected by serendipity. As in the case of decentralized firms we have to distinguish between two sub-cases denoted by $U s$ and $U c$, corresponding respectively to the case in which firms stop and continue to collude in the second market after the condemnation of the first one.

Case without LP: DJ do not consider the case $\mu_{2}<1$ then we first analyze the firms' strategies considering the case without LP. The expected profits and sustainability thresholds for the centralized firms are given by:

$$
\begin{array}{ccc}
\Pi_{i}^{U s}=\frac{\pi_{i}^{c U}-2\left[1+(1-\rho) \mu_{2}\right] \rho F}{1-\delta(1-\rho)^{2}} & ; \quad \Pi_{i}^{U c}=\frac{\pi_{i}^{c U}-2\left[1+(1-\rho) \mu_{2}\right] \rho F+\delta 2 \rho(1-\rho)\left(1-\mu_{2}\right) \widetilde{\Pi}_{i}}{1-\delta(1-\rho)^{2}} \\
F_{U s} \equiv \frac{\delta(1-\rho)^{2}-\frac{1}{2}}{\delta(1-\rho)^{2}\left[1+(1-\rho) \mu_{2}\right] \rho} \pi_{i}^{c U} \quad ; \quad F_{U c} \equiv \frac{[1-\delta(1-\rho)]\left[\delta(1-\rho)^{2}-\frac{1}{2}\right] \pi_{i}^{c U}+\delta \rho(1-\rho)\left(1-\mu_{2}\right) \widetilde{\pi}_{i}^{c}}{\left\{\rho\left(1-\mu_{2}\right)+\left[1-\rho-\delta(1-\rho)^{2}\right]\left[1+(1-\rho) \mu_{2}\right]\right\} \delta(1-\rho) \rho}
\end{array}
$$

We determine the equilibrium strategies by comparing the expected profits. For $F \leq \widetilde{F}$ the relevant comparison relates to the choice between the $M c$ and $U c$ strategies. For $F>\widetilde{F}$ we compare the $M s$ strategy with the $U s$ one.

$$
\begin{aligned}
& \Pi_{i}^{U c} \geq 2 \Pi_{i}^{M c} \Leftrightarrow F \leq \frac{[1-\delta(1-\rho)]\left(\frac{\pi_{i}^{c U}}{2}-\pi_{i}^{c M}\right)-\mu_{2} \delta(1-\rho) \rho \widetilde{\pi}_{i}^{c}}{(1-\delta) \mu_{2}(1-\rho) \rho} \equiv F_{2} \\
& \Pi_{i}^{U s} \geq 2 \Pi_{i}^{M s} \Leftrightarrow F \leq \frac{\frac{\pi_{i}^{c U}}{2}-\pi_{i}^{c M}}{(1-\rho) \mu_{2} \rho} \equiv F_{3}
\end{aligned}
$$

If $F \leq \widetilde{F}$ centralized firms can continue to collude (with probability $1-\mu_{2}$ ) in the second market once the first cartel has been detected. Then the $U c$ strategy can appear at equilibrium for low values of $F$ and $d$ sufficiently high. For low values of $d$ the $M c$ strategy is still an equilibrium since compartmentalization is perfect only for decentralized firms. A decreased value of $\mu_{2}$ decreases the expected fine and increases the profit under the $U s$ strategy which is then sustainable for increased values of $F$. As the expected profits under the $U c$ and $U s$ strategies increase whereas they remain the same for decentralized firms then the border lines $F_{2}$ and $F_{3}$ move to the left.

Proposition 6 A decreased value of $\mu_{2}$ provides stronger incentives to choose a U-form design since it makes collusion easier to sustain for centralized firms.

The figure 6 serves to illustrate these results for $\mu_{2}=0.6$ (we also plot the border lines obtained for $\mu_{2}=1$ with dots).

\footnotetext{
${ }^{35}$ We assume that $\mu_{2}>\mu_{3}=0$.
} 


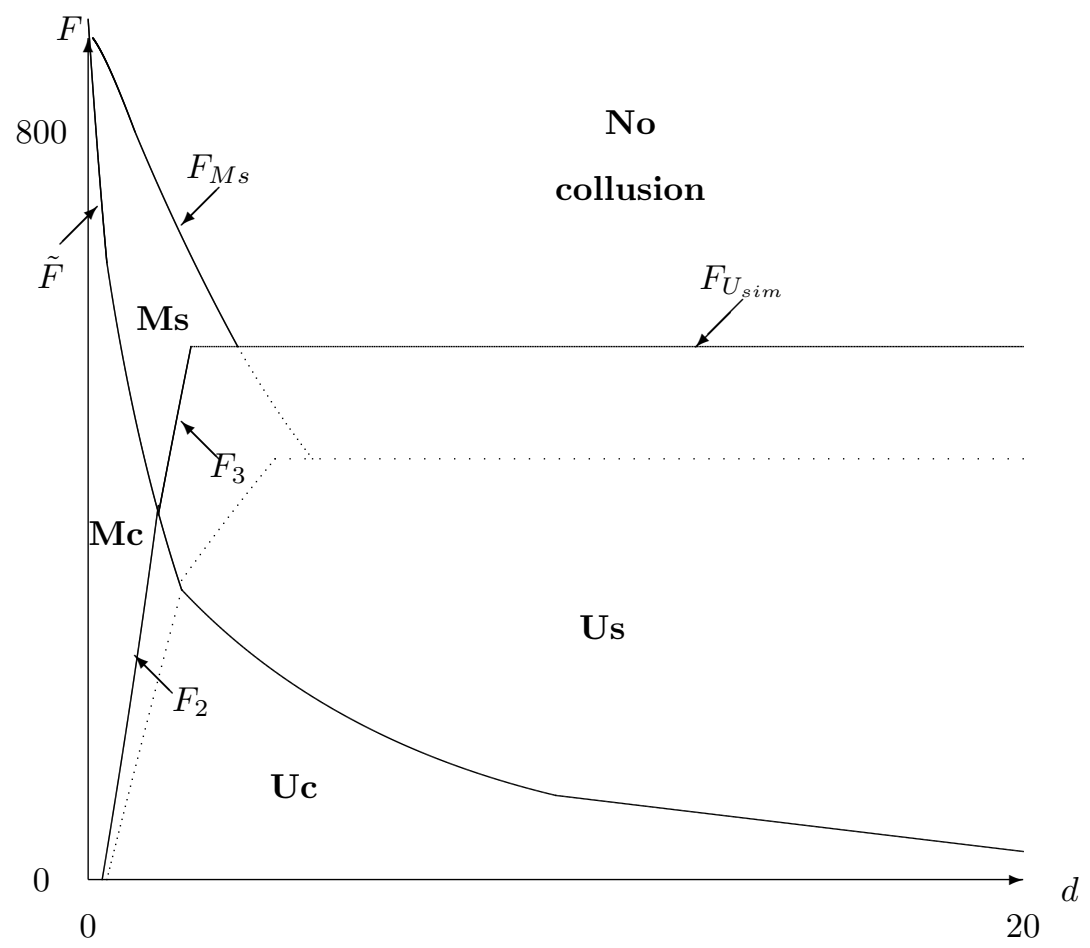

Figure 6: Equilibrium organizational structures without LP and for $\mu_{2}=0.6$.

Scenario S: We prove in the section 4.1 that the only impact of the LP under scenario $\mathrm{S}$ is to modify sustainability conditions implying that all the border lines move downward.

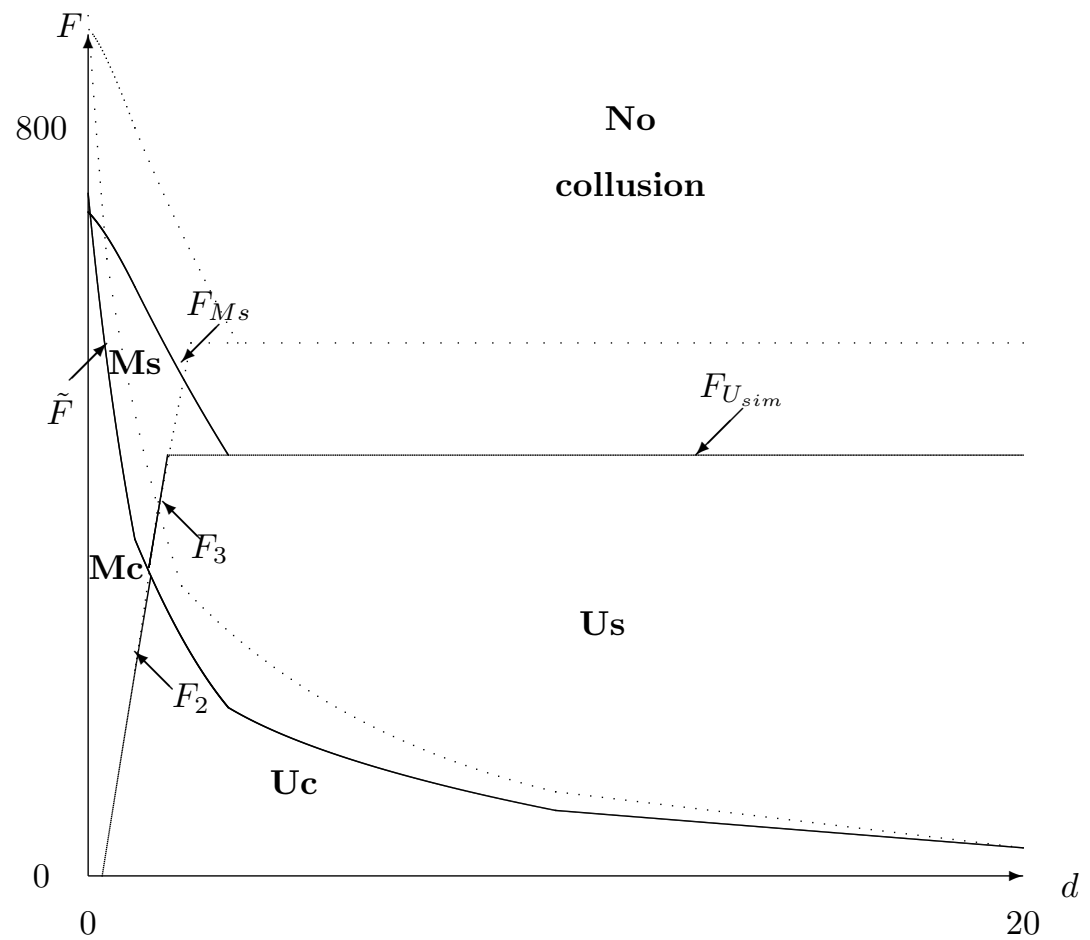

Figure 7: Equilibria obtained with scenario $\mathrm{S}$ and $\mu_{2}=0.6$. 
The expressions of $F_{M s}, F_{M c}$ and $\widetilde{F}$ remain the same and the expressions of $F_{U s}$ and $F_{U c}$ are indicated below:

$$
F_{U s} \equiv \frac{\delta(1-\rho)^{2}-\frac{1}{2}}{\left[1+(1-\rho) \mu_{2}\right] \rho} \pi_{i}^{c U} ; F_{U c} \equiv \frac{[1-\delta(1-\rho)]\left[\delta(1-\rho)^{2}-\frac{1}{2}\right] \pi_{i}^{c U}+\delta \rho(1-\rho)\left(1-\mu_{2}\right) \tilde{\pi}_{i}^{c}}{\left\{\delta \rho(1-\rho)\left(1-\mu_{2}\right)+[1-\delta(1-\rho)]\left[1+(1-\rho) \mu_{2}\right]\right\} \rho}
$$

Results obtained in the section 4.1 can be generalized for the case $\mu_{2}<1$. The presence of the LP does not alter the previous effects obtained without LP: the border lines $F_{2}$ and $F_{3}$ move to the left favoring the adoption of the U-form organization.

We illustrate these results with the figure 7 (border lines obtained without LP are plotted with dots).

Scenario L: The problem faced by the centralized firms after the detection of the first cartel (stage 6) closely seems to the decentralized firms' one with $\mu_{3}>0$. If the firms play the $U s$ strategy they always apply for leniency once the first cartel has been detected and they have a fifty-fifty chance of being the first one. The expected fine for the second cartel is then $\frac{1}{2} F$ whereas it is $\mu_{2} F$ under scenario $\mathrm{S}$ and without LP. Thus expected profit of the $U s$ strategy is decreased if $\mu_{2}<\frac{1}{2}$ and increased otherwise. Expected profits of the $U s$ strategy and sustainability conditions are the same as in the section 4.2 (for the $U_{\text {sim }}$ strategy). The expressions of $\widetilde{\Pi}_{i}, \Pi_{i}^{M c}, \Pi_{i}^{M s}, F_{M s}, F_{M c}, \widetilde{F}, F_{2}$ and $F_{3}$ remain unchanged also.

Firms playing the $U c$ strategy shall not be induced to reveal the second cartel once the first one has been detected. If a firm believes that the other firm does not apply for leniency then it obtains an expected profit of 0 applying for leniency and $\left(1-\mu_{2}\right) \widetilde{\Pi}_{i}-\mu_{2} F$ otherwise. Firm applies for leniency if and only if:

$$
\left(1-\mu_{2}\right) \widetilde{\Pi}_{i}-\mu_{2} F<0 \Leftrightarrow F>\frac{\left(1-\mu_{2}\right) \widetilde{\pi}_{i}^{c}}{\rho\left(1-\mu_{2}\right)+[1-\delta(1-\rho)] \mu_{2}} \equiv F_{\text {report }} \Leftrightarrow \frac{\tilde{\pi}_{i}^{c}-\rho F}{[1-\delta(1-\rho)] F+\widetilde{\pi}_{i}^{c}-\rho F}<\mu_{2}
$$

An increased value of $\mu_{2}$ can make the $U c$ strategy unsustainable. The border line between the $U c$ and $M c$ strategies is the same as without LP (firms do not apply for leniency when they play these two strategies) and is denoted $F_{2 a}$. The border line between the $U s$ and $M c$ strategies is denoted $F_{2 b}$.

Multiple and ambiguous effects of the LP appear in scenario L if $\mu_{2}<1$.

Firstly there is an area where the LP have pro-competitive effects providing firms to switch from the $U c$ strategy to the $U s$ one.

Secondly when $\mu_{2}=1$ the switch from the benchmark case or scenario $\mathrm{S}$ to scenario L yields to an increased expected profit under the $U s$ strategy, the border line $F_{U_{s i m}}$ moves upward and $F_{3}$ moves to the left. Considering $1 / 2<\mu_{2}<1$ does not qualitatively modify the effects on expected profits and $F_{3}$, it is not the case otherwise. If $\mu_{2}>1 / 2$ the border line $F_{U_{s i m}}$ moves upward when we switch from scenario $\mathrm{S}$ to scenario $\mathrm{L}$, it is the opposite case if $\mu_{2}<1 / 2$. The comparison of scenario $\mathrm{L}$ with the benchmark case is more complicated. The expected profit increases [decreases] if $\mu_{2}>1 / 2\left[\mu_{2}<1 / 2\right]$ and the border line moves upward [downward]. Simultaneously deviation profits are increased causing the border line moving downward. The threshold value of $\mu_{2}$ above which the border line $F_{U \text { sim }}$ moves upward (when we introduce 
scenario L) is strictly higher than $1 / 2$ and is: $\frac{3-\rho}{2 \delta(1-\rho)^{3}}-\frac{1}{1-\rho} \cdot 36$

Thirdly the effect on the border line between the $U$ and $M c$ areas for $F_{\text {report }}<F<\widetilde{F}$ is ambiguous. In this area $U c$ is not sustainable under scenario $\mathrm{L}$ and firms can only choose the $U s$ or $M c$ strategy, then firms either choose to maintain higher equilibrium prices on the two markets ( $U$ strategy) or they choose to continue to collude in the other once the first one has been detected ( $M c$ strategy). Profits under the $U s$ strategy in scenario L are not necessarily lower than those of the $U c$ strategy in scenario $\mathrm{S}$. $\Pi_{i}^{U s}$ is increased if $\mu_{2}>1 / 2$ and, for some values of $F, \Pi_{i}^{U s}$ is higher than the previous value of $\Pi_{i}^{U c}$. The border line $F_{2 b}$ realizes a rotation with respect to the initial border line: it moves to the right for low values of $F$ and to the left otherwise. For low values of $F$ applying for leniency can be considered as a prisoner dilemma: it is a dominant strategy but it decreases the expected profits of the firms when they both apply. For high values of $F$ firms collectively have an interest in applying for leniency since they obtain reduced fine higher than the loss of profits according to the second cartel. So firms have stronger incentives to choose the M-form organization for low values of $F$ and to adopt the U-form one for higher values of the fine.

Proposition 7 If $\mu_{2}<0.5$, allowing leniency applications during the investigation process decreases opportunities for centralized firms to make collusive agreements and may drive firms to adopt a more decentralized organization.

We obtain opposite results compared to the case $\mu_{2}=1$.

Proposition 8 If $\mu_{2}>0.5$, allowing leniency applications during the investigation process decreases [extends] opportunities for centralized firms to make collusive agreements if $F$ is low [high].

Corollary 9 If $\mu_{2}>0.5$, allowing leniency applications during the investigation process may drive firms to adopt the M-form [U-form] organization if $F$ is low [high].

The policy implications seem to be that if the antitrust authorities already have high deterring capacities ( $\mu_{2}$ high and/or $F$ high) they should not allow leniency applications for a second cartel once a first one has been detected. Nonetheless in the opposite case they should allow leniency applications during the investigation process.

The figure 8 helps to illustrate some of the previous results for $\mu_{2}=0.6$ (border lines obtained without the LP and S are plotted with dots).

Since the figure is plotted for $\mu_{2}>0.5, \Pi_{i}^{U s}$ is increased with the possibility for firms to apply for leniency for a second cartel once the first one has been detected. This strategy is then easier to sustain than in scenario $\mathrm{S}$. The value of $F_{U s}$ is lower than in the benchmark case but the opposite can be true if $\mu_{2}$ is relatively high (as is the case in the section 4.2 for $\mu_{2}=1$ ). The increased value of $\Pi_{i}^{U s}$ switches the border line $F_{3}$ to the 36

$$
\frac{2 \delta(1-\rho)^{2}-1}{(3-\rho) \rho} \pi_{i}^{c U} \geq \frac{\delta(1-\rho)^{2}-\frac{1}{2}}{\delta(1-\rho)^{2}\left[1+(1-\rho) \mu_{2}\right] \rho} \pi_{i}^{c U} \Leftrightarrow \mu_{2} \geq \frac{3-\rho}{2 \delta(1-\rho)^{3}}-\frac{1}{1-\rho}
$$


left increasing the U-form organization area. Effects would be opposite for $\mu_{2}<0.5$ and firms may switch to decentralized structure.

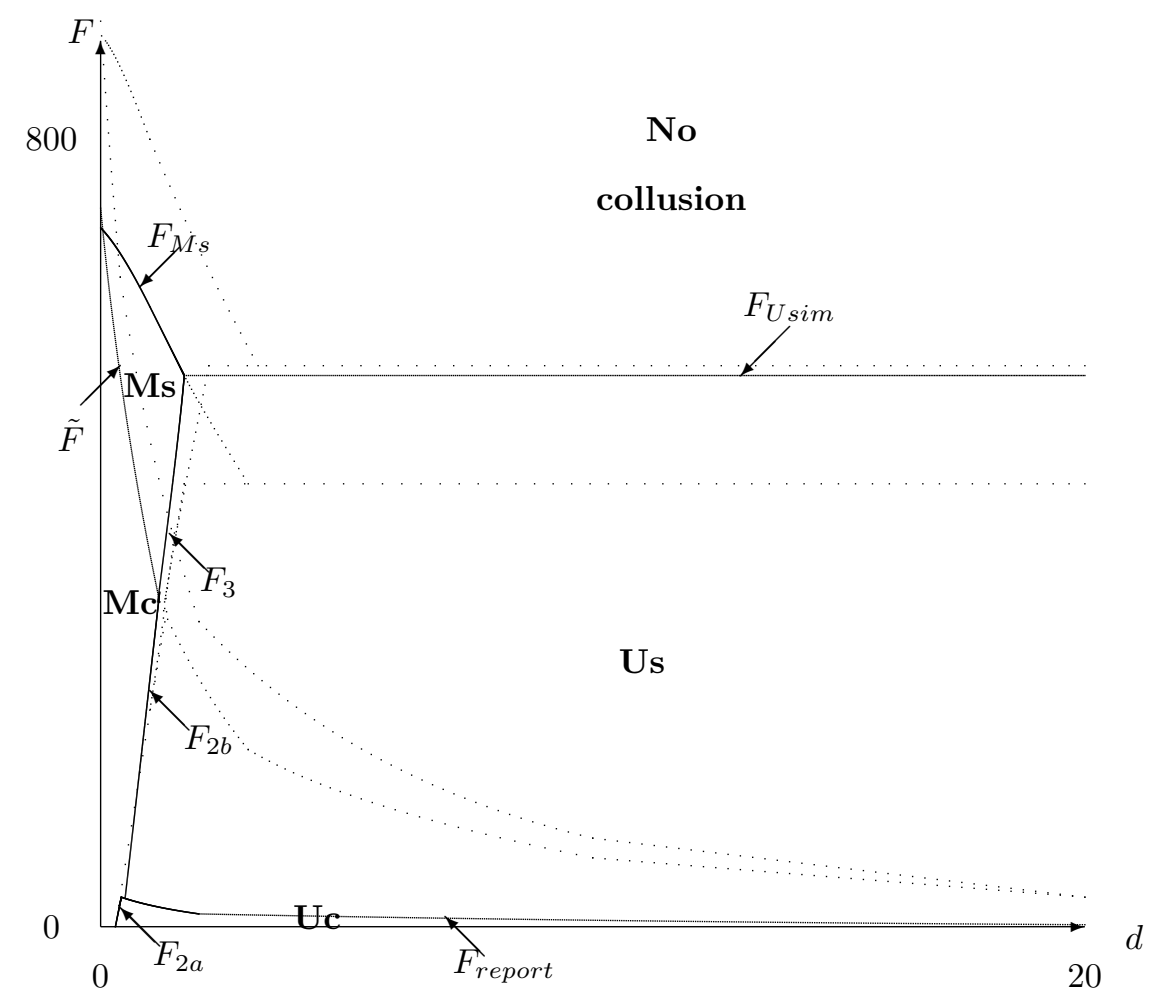

Figure 8: Equilibria obtained with scenario L and $\mu_{2}=0.6$.

Scenario S+: Firms playing the $U s$ strategy systematically apply for the AP whenever it is possible. Then profit is decreased since firms can apply for the AP only after the antitrust authority fails to detect the second cartel. This cartel is then revealed by the firms obtaining a reduced fine $(1-\tau) F$ with probability 0.5 concerning the first cartel and they pay $F$ with probability 0.5 . The border line $F_{3}$ keeps moving to the left since the reduction of the profits is higher under the $M s$ strategy than the $U s$ one (the negative effect appears with probability 1 under the $M s$ strategy and probability $1-\mu_{2}$ under the $U s$ one).

In order to play the $U c$ strategy firms should not be induced to reveal the second cartel once the first one has been detected. Centralized firms must await the completion of the investigation (stage 8) before being able to reveal the second cartel. If the second cartel has been detected during the investigation firms can not benefit from the AP. In the opposite case, firms are in the same situation than decentralized firms in the section 5.1: they obtain $\widetilde{\Pi}_{i}$ if they collude in the second market but fine is reduced for the first cartel of $(1-\tau) F$ if they reveal the information. The same condition applies as in the case of firms playing the $M c$ strategy (section 5.1). Firms can play the $U c$ strategy only if: $F \leq F_{\text {report }}=\frac{\widetilde{\pi}_{i}^{c}}{[1-\delta(1-\rho)](1-\tau)+\rho}$.

The AP reduce opportunity for centralized and decentralized firms to make collusive agreements. The possibility for firms to collude in the second market once the first cartel has been successfully detected is harder to sustain with the AP. The border lines $F_{U \text { sim }}$ and $F_{M s}$ move downward and then opportunity to 
collude in the first cartel is also reduced. The AP have clear anti-collusive effects.

We obtain the following proposition: ${ }^{37}$

Proposition 10 The introduction of the AP reduces opportunities for decentralized and centralized firms to make collusive agreements and may drive firms to adopt a more centralized organization.

The AP may drive firms to switch from a decentralized organization to a centralized one inducing collusive prices increase.

Proposition 11 The introduction of the AP may lead to anticompetitive effects since collusive prices can increase.

The figure 9 serves to illustrate the equilibria for $\tau=0.5, \mu_{2}=0.6$ and high value of $\sigma$ (we plot the border lines obtained in scenario $\mathrm{S}$ with dots).

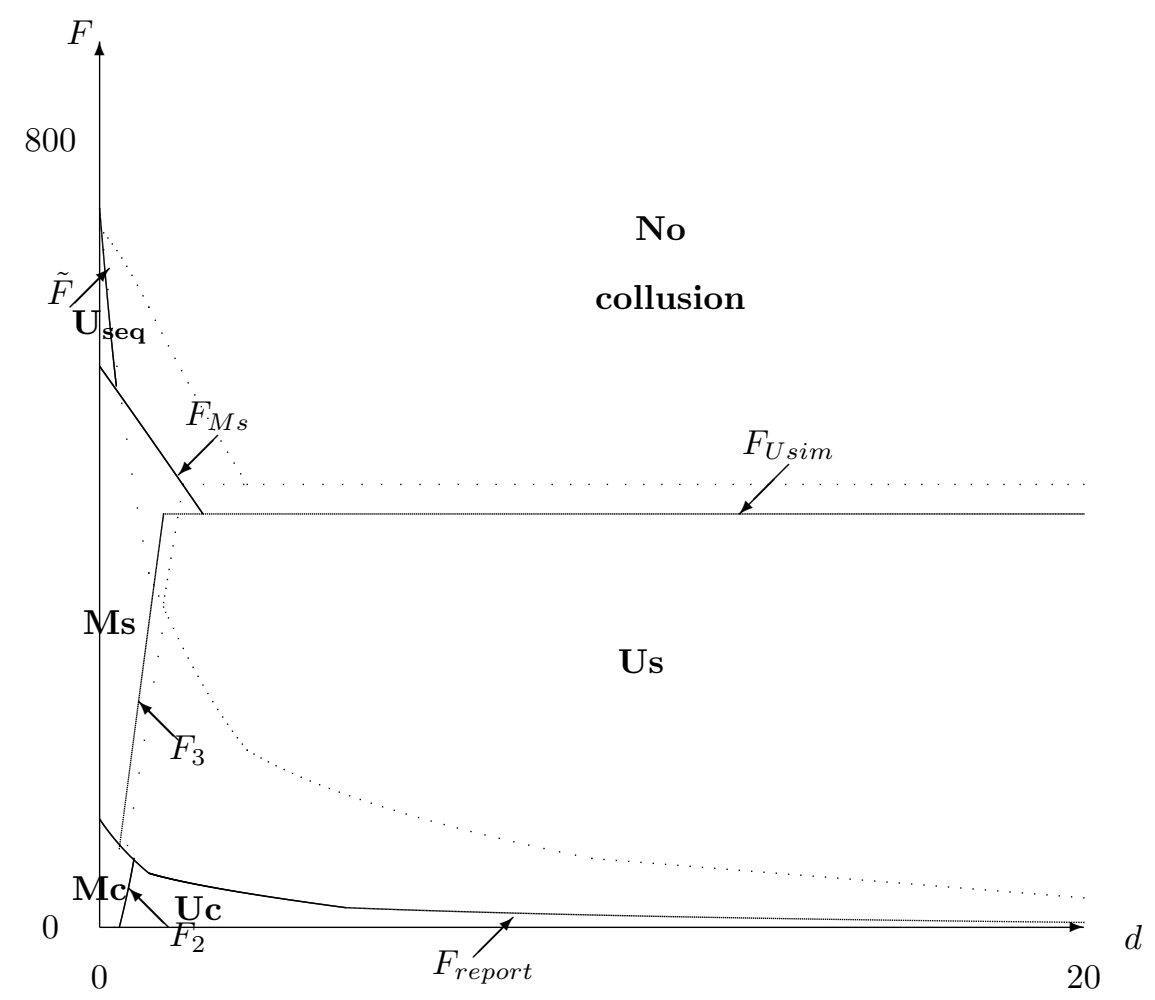

Figure 9: Equilibria obtained with scenario $\mathrm{S}+$ with $\mu_{2}=0.6$.

Scenario L+: Firms playing the $U s$ strategy systematically apply for the AP once the first cartel has been detected. Then profits under the $U s$ strategy are increased. The simple LP were sufficient to induce firms to reveal the second cartel. Under the AP firms get an additional reduction for the fine of $(1-\tau) F$ ${ }^{37}$ The proposition 4 remains valid 
for the first cartel with probability 0.5 giving nothing in return. The introduction of the AP may drive firms to adopt a more centralized structure since firms playing the $M s$ strategy systematically reveal the second cartel removing advantages of the $M s$ strategy compared to the $U s$ one.

In order to play the $U c$ strategy firms should not be induced to reveal the second cartel after the first one has been detected. If they choose not to cooperate with the antitrust authority at stage 6 , firms can expect a global pay-off: $\left(1-\mu_{2}\right) \widetilde{\Pi}_{i}-\mu_{2} F$, in the opposite case a firm obtains a reduced fine for the first cartel of $(1-\tau) F$ and avoids the second fine (if the other firm does not cooperate). Firms apply for leniency if:

$$
(1-\tau) F>\left(1-\mu_{2}\right) \widetilde{\Pi}_{i}-\mu_{2} F \Leftrightarrow F>\frac{\left(1-\mu_{2}\right) \widetilde{\pi}_{i}^{c}}{[1-\delta(1-\rho)]\left(1-\tau+\mu_{2}\right)+\left(1-\mu_{2}\right) \rho} \equiv F_{\text {report } 2}
$$

The $M s$ strategy is now always dominated by the $U s$ one. Expressions of $F_{U s}$ and $F_{\text {report }}$ concerning the $M c$ strategy are the same as those used in the section 5.2. $F_{2 a}$ is the same as in scenario $\mathrm{S}+$ since expected profits under the $M c$ and $U c$ strategies are unchanged. $F_{2 b}$ (border line between $M c$ and $U s$ ) is the same as in the section 5.2 .

The figure 10 serves to illustrate the equilibria for $\tau=0.5, \mu_{2}=0.6$ and high value of $\sigma$.

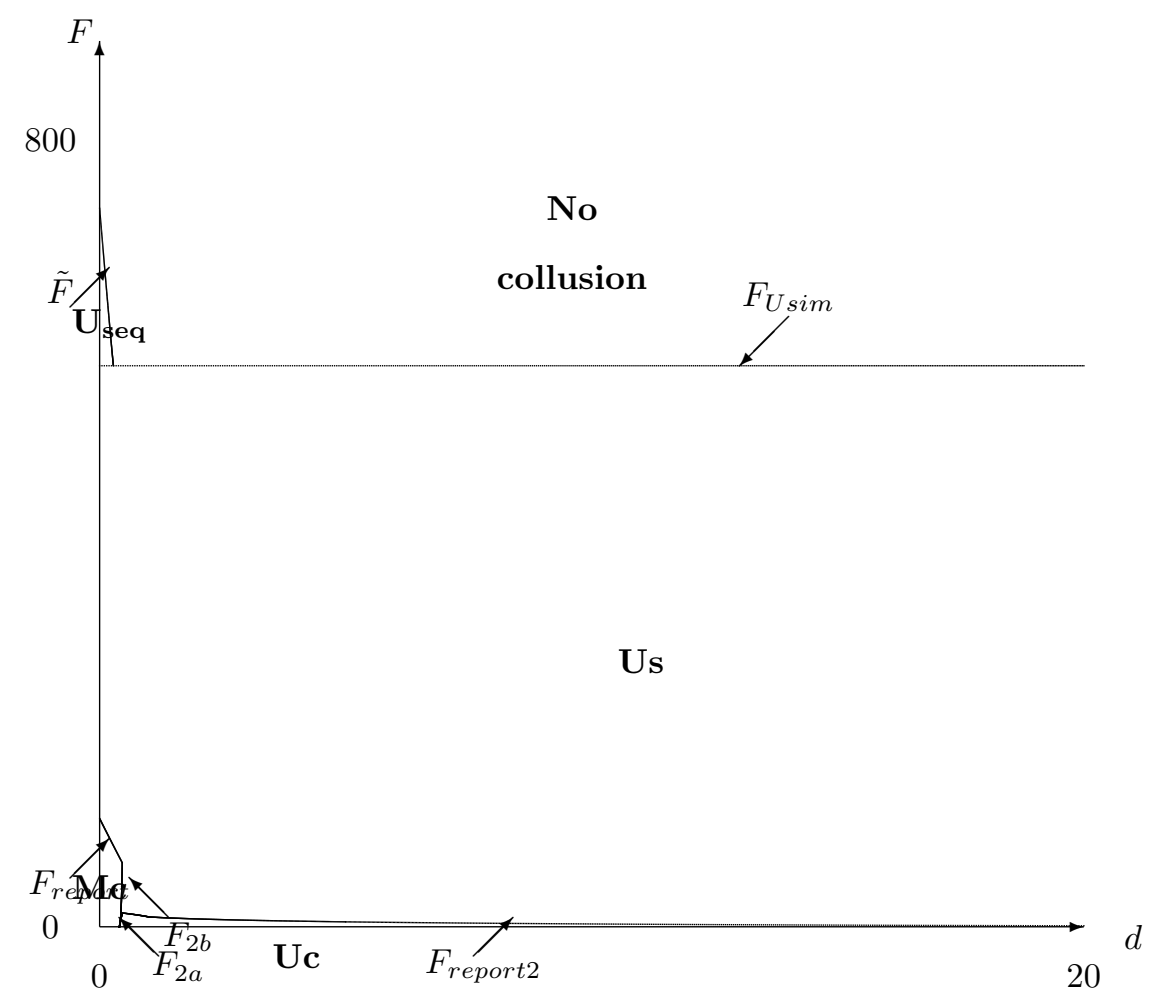

Figure 10: Equilibria obtained in scenario L + with $\mu_{2}=0.6$.

The AP decrease the threshold value of $F$ above which centralized firms stop collusion in the second market and reveal the information to the antitrust authority as soon as the first cartel has been detected. The $U c$ area is significantly reduced implying that the AP have pro competitive effects. But the AP also produce pro-collusive effects: firms may switch from the decentralized organization to the centralized one 
yielding to a price increase. Moreover the border line $F_{U_{\text {sim }}}$ moves upward and then the introduction of the AP may extend opportunities for centralized firms to make collusion.

The proposition 5 remains valid: the AP lead to higher expected profits under the $U_{\text {sim }}$ strategy and may drive firms to choose a centralized structure.

The comparison of the scenarios $\mathrm{L}+$ and $\mathrm{S}+$ produces qualitatively similar results. $F_{\text {report } 2}$ is lower than $F_{\text {report }}$, it is harder to sustain $U c$ in scenario $\mathrm{L}+$ than in $\mathrm{S}+$. Allowing firms to apply for leniency in stage 6 can have pro-competitive effects. But firms may switch from the decentralized organization to the centralized one yielding to a price increase. Moreover $F_{U_{s i m}}$ moves upward. Collusion becomes sustainable in an area where it was not in scenario $\mathrm{S}+$.

\subsection{Decentralization slows down investigation (alternating timing)}

In the main part of the article we study two timings of the LP considering scenario $\mathrm{S}$ (Short investigations) and scenario L (Long investigations). However in both cases the timing is the same whatever the organizational structure is. But it can be envisaged that the detection of the second cartel is faster for the centralized firms. In this section we consider that leniency can be applied for the second cartel only for decentralized firms since the investigation is longer (we suppose that cartels are quite simultaneously detected for centralized firms).

If $\mu_{3}=0$ this alternative timing corresponds to the timing analyzed in the section 4.1 . The opposite case $\mu_{3}=1$ is more interesting since it removes cases where firms choose the decentralized organization to benefit from a lower probability of detection by serendipity. If $\mu_{2}=1$ and $\mu_{3}=1$ only the $M s, U_{\text {sim }}$ and $U_{\text {seq }}$ strategies are available and the $M s$ one is always dominated by the $U_{\text {sim }}$ one if the timings are equivalent for each type of firm thus decentralization of activities is not an equilibrium. By contrast different timings as explained above may lead to the adoption of decentralized structure.

Without LP firms never choose a decentralized structure since the $M c$ strategy is not possible and the $M s$ one is dominated by the $U_{\text {sim }}$ strategy. Then only one relevant border line must be computed:

$$
\Pi_{i}^{U_{\text {sim }}} \geq \Pi_{i}^{U_{\text {seq }}} \Leftrightarrow F \leq \frac{[1-\delta(1-\rho)]^{2} \pi_{i}^{c U}-\left[1-\delta(1-\rho)^{2}\right](1-\delta+2 \delta \rho) \widetilde{\pi}_{i}^{c}}{\left\{2[1-\delta(1-\rho)]^{2}(2-\rho)-\left[1-\delta(1-\rho)^{2}\right](1-\delta+2 \delta \rho)\right\} \rho} \equiv F_{1}
$$

We introduce the LP. For the centralized firms we obtain the same effects as in the section 4.1. By contrast the expected profit under the $M s$ strategy is altered and we obtain the following expressions:

$$
\Pi_{i}^{M s}=\frac{\pi_{i}^{c M}-\frac{1}{2}(3-\rho) \rho F}{1-\delta(1-\rho)^{2}} \quad ; \quad F \leq \frac{2 \delta(1-\rho)^{2}-1}{\frac{1}{2}(3-\rho) \rho} \pi_{i}^{c M} \equiv F_{M s}
$$

The relevant border lines are:

$$
\begin{aligned}
& \Pi_{i}^{U_{\text {sim }}} \geq 2 \Pi_{i}^{M s} \Leftrightarrow F \leq \frac{\pi_{i}^{c U}-2 \pi_{i}^{c M}}{(1-\rho) \rho} \equiv F_{3} \\
& \Pi_{i}^{U_{\text {seq }}} \geq 2 \Pi_{i}^{M s} \Leftrightarrow F \geq \frac{2[1-\delta(1-\rho)]^{2} \pi_{i}^{c M}-\left[1-\delta(1-\rho)^{2}\right](1-\delta+2 \delta \rho) \widetilde{\pi}_{i}^{c}}{\left\{[1-\delta(1-\rho)]^{2}(3-\rho)-\left[1-\delta(1-\rho)^{2}\right](1-\delta+2 \delta \rho)\right\} \rho} \equiv F_{4}
\end{aligned}
$$


The introduction of the LP allows to create a new graphical area where $M s$ is selected (in spite of $\mu_{3}=1$ ). Firms choose a decentralized organization despite lower collusive prices in order to slow down the authority investigations which allows them to apply for leniency for the second cartel (the expected fine is then $0.5 F$ ).

The introduction of the AP leads to an even larger reduction in expected fine $(0.5(1+\tau) F)$. The border line $F_{M s}$ moves upward and $F_{3}$ moves to the right.

Proposition 12 The introduction of the LP may drive firms to adopt a more decentralized structure in order to slow down the authority investigations. This effect is reinforced as the AP are introduced.

Overall the LP have mainly pro competitive effects. The border line $F_{U s i m}$ moves downward and collusion is then more difficult to sustain. Moreover firms may switch from the $U_{\text {sim }}$ strategy to the $M s$ one leading to a price decrease. However there is an area where firms switch from the $U_{\text {seq }}$ strategy to the $M s$ one leading to a price increase together with shorter lasting collusion.

The Figure 11 serves to illustrate these results ${ }^{38}$ (we also plot on the graph the border lines obtained without LP with dots).

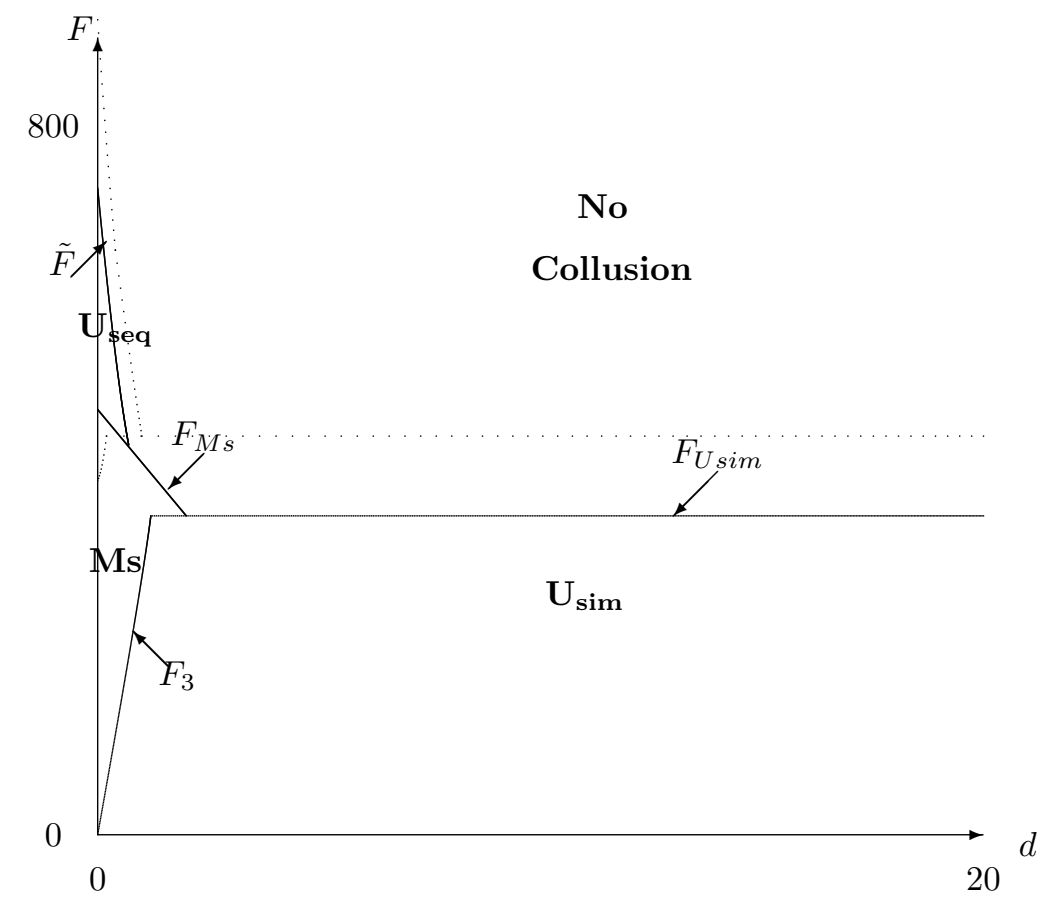

Figure 11: Equilibria obtained in the alternating timing.

\subsection{Ineffective audits (low value of $\sigma$ )}

In the section 5 we consider $\sigma>\frac{2-2 \tau}{3-2 \tau}$ implying that managers cooperate with the CEO if there is internal audit. In this section we analyze the opposite case: $\sigma<\frac{2-2 \tau}{3-2 \tau}$. The value of $\sigma$ impacts only scenarios $\mathrm{S}+$ and $\mathrm{L}+$.

\footnotetext{
${ }^{38}$ The border line $F_{4}$ does not exist since $U s e q$ is always dominated by $M s$ when the latter is sustainable
} 


\subsubsection{Scenario $\mathrm{S}+$}

If the firms play the $M s$ strategy the CEOs always wish to apply for the AP and managers pass on evidences to their CEO as soon as $\sigma>0$. If the firms play the $M c$ strategy a CEO wishes to apply for the AP if:

$$
(1-\tau) F \geq \widetilde{\Pi}_{i} \Leftrightarrow F \geq \frac{\widetilde{\pi}_{i}^{c}}{[1-\delta(1-\rho)](1-\tau)+\rho} \equiv F_{\text {report }}
$$

A manager desires to pass on hard evidence to his CEO if:

$$
\frac{1}{2} \frac{\sigma}{1-\sigma} F \geq \widetilde{\Pi}_{i} \Leftrightarrow F \geq \frac{2(1-\sigma) \widetilde{\pi}_{i}^{c}}{\sigma-\delta(1-\rho) \sigma+2(1-\sigma) \rho} \equiv F_{\text {coop }}
$$

Since $F_{\text {report }}<F_{\text {coop }}$ then for some values of $F$ the CEOs conduce internal audits to obtain proofs concerning the second cartel but managers try to hide them in order to continue to collude in the second market. In this case collusion in the second market is pursued with probability $(1-\sigma)^{2}$ once the first cartel has been detected. If $F<F_{\text {report }}$ the CEOs do not want to apply for leniency (expressions are the same as in the section 5.1). If $F>F_{\text {coop }}$ the CEOs wish to denounce the second cartel and managers have an interest to pass on evidences. The $M c$ strategy is no longer viable (as in the section 5.1). The only changes are thus in the interval $\left[F_{\text {report }}, F_{\text {coop }}\right]$.

The expected profits of the firms playing the $M c$ strategy is the following:

$$
\Pi_{i}^{M c}=\left\{\begin{array}{c}
\frac{\pi_{i}^{c M}-\rho F+\delta(1-\rho) \rho \widetilde{\Pi}_{i}}{1-\delta(1-\rho)^{2}} \quad \text { if } F<F_{\text {report }} \\
\frac{\pi_{i}^{c M}-\left[1+(1-\rho)\left(1-\frac{1}{2} \sigma\right) \sigma \tau\right] \rho F+\delta(1-\rho) \rho(1-\sigma)^{2} \widetilde{\Pi}_{i}}{1-\delta(1-\rho)^{2}} \quad \text { if } F_{\text {report }}<F<F_{\text {coop }}
\end{array}\right.
$$

The border line between $U_{\text {sim }}$ and $M c$ is not altered if $F<F_{\text {report }}$. In the opposite case the border line is:

$$
\Pi_{i}^{U_{s i m}} \geq 2 \Pi_{i}^{M c} \Leftrightarrow F \leq \frac{[1-\delta(1-\rho)]\left(\frac{\pi_{i}^{c U}}{2}-\pi_{i}^{c M}\right)-\delta(1-\rho) \rho(1-\sigma)^{2} \tilde{\pi}_{i}^{c}}{\left\{[1-\delta(1-\rho)]\left[1-\left(1-\frac{1}{2} \sigma\right) \sigma \tau\right]-\delta \rho(1-\sigma)^{2}\right\}(1-\rho) \rho} \equiv F_{2 b}
$$

The border line $F_{2 b}$ is to the right of $F_{3}$ which was the relevant border line for high value of $\sigma$. Less successful audit may lead firms to switch from the $U_{\text {sim }}$ strategy to the $M c$ one with an apply for the AP when the internal audit was successful. The border line $F_{2 b}$ is to the left of $F_{2 a}$ which would be the relevant border line without AP. So we can generalize the proposition 4 considering low values for $\sigma$ : the introduction of the AP may drive firms to adopt a more centralized organization.

The figure 12 serves to illustrate the equilibria for $\tau=0.5$ and $\sigma=0.3$.

The main difference with the graphical representation obtained in the section 5.1 is the emergence of the $\operatorname{Mcr}(M c$ with report) area: firms choose a decentralized structure and simultaneously collude in the two markets. Once the collusion is detected in one market CEO and managers do not agree on how to proceed. The CEOs wish to denounce the second cartel but the managers have an interest to continue to collude: the CEOs launch internal audit and managers do not pass on evidences. The second cartel continues to exist with probability $(1-\sigma)^{2}$. 


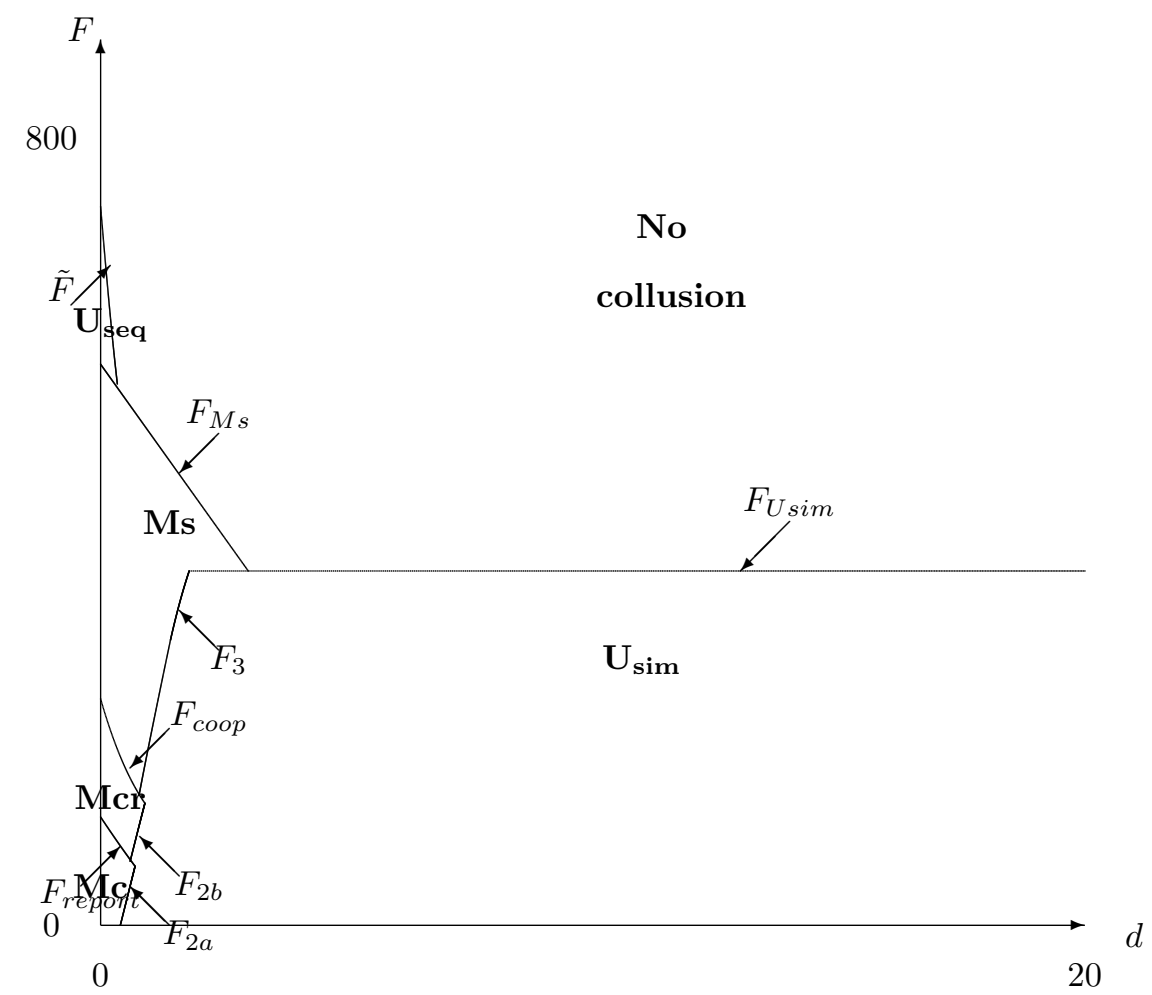

Figure 12: Equilibria obtained in scenario $\mathrm{S}+$ with low value of $\sigma$.

Impact of $\sigma:$ If firms play the $M s$ strategy then two cases have to be analyzed: if $\sigma=0$ then managers do not cooperate and the second cartel is not detected ; if $\sigma>0$ then managers cooperate and the second cartel is detected with probability $1 . \Pi_{i}^{M s}$ is higher in the first case (it is a decreasing function of $\sigma$ ).

If firms play the $M c$ strategy we obtain the following result:

$$
\frac{\partial \Pi_{i}^{M c}}{\partial \sigma}=\frac{-(1-\sigma) \tau(1-\rho) \rho F-2 \delta(1-\rho) \rho(1-\sigma) \widetilde{\Pi}_{i}}{1-\delta(1-\rho)^{2}}<0 \quad \text { if } F_{\text {report }}<F<F_{\text {coop }}
$$

An increased value of $\sigma$ leads to a profit decrease under the $M c$ strategy and firms switch to the $M s$ strategy if $\sigma>\frac{2-2 \tau}{3-2 \tau}$. An increased value of $\sigma$ leads to a profit decrease for decentralized firms since it reduces the opportunities of compartmentalization.

Ideally firms may commit on $\sigma=0$ during the negotiation of the collusive agreements. However each CEO wishes to increase this probability to apply for the AP once the first cartel has been detected. Firms collectively prefer $\sigma=0$ but individually they prefer $\sigma>0$ (prisoner dilemma situation). Then if $\sigma$ was endogenous and if there was no cost to increase this value then firms would choose $\sigma=0$ if this choice was cooperative (and observable) and $\sigma=1$ if the choice was unobservable.

Proposition 13 An increased value of $\sigma$ leads to decrease profit for the decentralized firms and may drive firms to adopt a more centralized organization. 


\subsubsection{Scenario $\mathrm{L}+$}

Since $\mu_{3}=0$ the two scenarios are equivalent for decentralized firms. However $\Pi_{i}^{U_{s i m}}$ is increased (as in the section 5.2) which changes the comparison between $M c$ and $U_{\text {sim }}$. If $F<F_{\text {report }}$ the border line $F_{2}$ is the same as in the section 5.2. In the opposite case $\left(F_{\text {report }}<F<F_{\text {coop }}\right)$ the expression of the border line must be computed:

$$
\Pi_{i}^{U_{s i m}} \geq 2 \Pi_{i}^{M c} \Leftrightarrow F \leq \frac{[1-\delta(1-\rho)]\left(\pi_{i}^{c U}-2 \pi_{i}^{c M}\right)-2 \delta(1-\rho) \rho(1-\sigma)^{2} \widetilde{\pi}_{i}^{c}}{\left\{[1-\delta(1-\rho)][1-(2-\sigma) \sigma] \tau-2 \delta \rho(1-\sigma)^{2}\right\}(1-\rho) \rho} \equiv F_{2 b}
$$

This border line moves to the left: allowing for leniency during the investigation increases the value of $\Pi_{i}^{U_{\text {sim }}}$ and may drive firms to adopt a unitary organizational structure.

The figure 13 illustrates the results obtained with $\tau=0.5$ and $\sigma=0.3$.

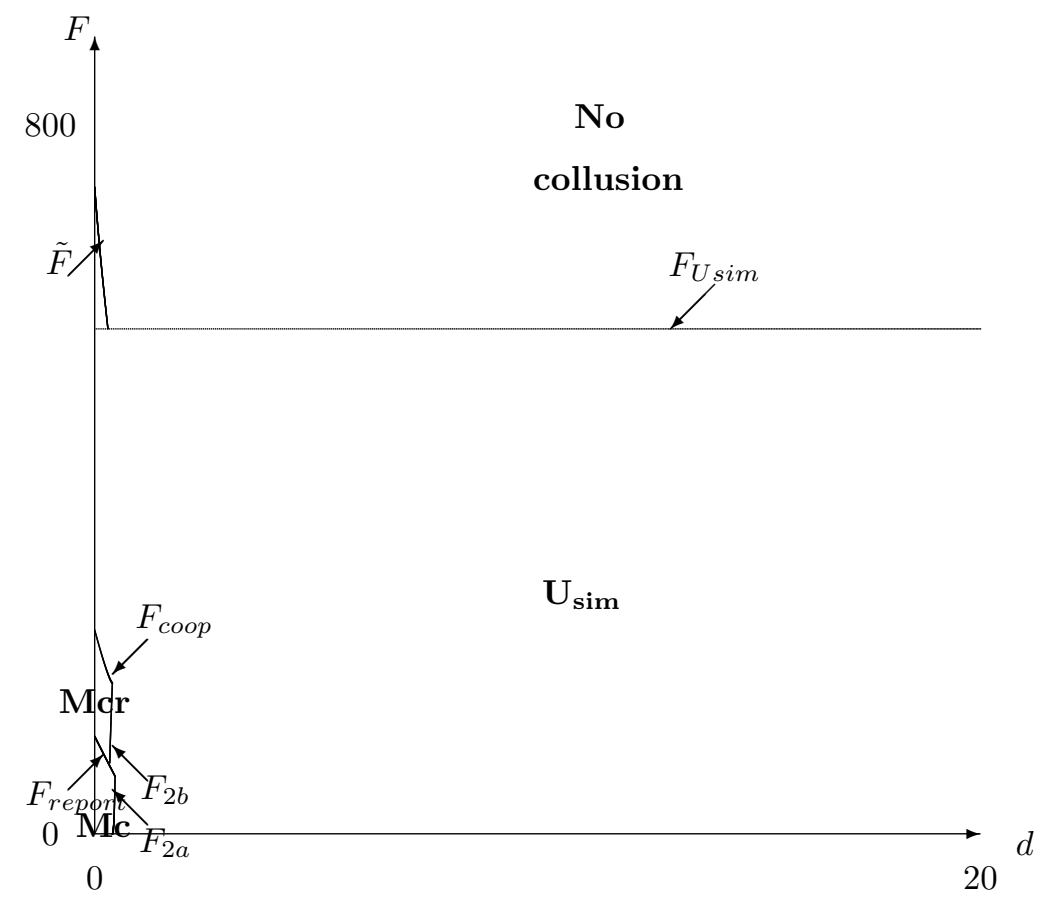

Figure 13: Equilibria obtained in scenario $\mathrm{L}+$ with low value of $\sigma$.

As in the previous case a $M c r$ area appears (compared to the figure in the section 5.2). The proposition 5 remains valid if we consider a low value of $\sigma$. The proposition 13 remains valid as well.

\subsection{Costly audits $(k>0)$}

We now consider the case in which internal audits are expensive. ${ }^{39}$ The $k$ value impacts equilibria only under the scenarios $\mathrm{S}+$ and $\mathrm{L}+$. We assume high value of $\sigma$. If $k=0$ firms playing the $M s$ strategy systematically

\footnotetext{
${ }^{39} \mathrm{~A}$ study by the French antitrust authority based on firms and specialist lawyers indicates that the global cost of a leniency application can range in size from thousand to several million Euros. These costs include 'the mobilisation of the employees [...] to carry out an internal investigation' (Autorité de la concurrence, 2014).
} 
apply for leniency once the first cartel has been detected. If $k>0$ and the other firm does not apply for leniency then firm applies only if $k<(1-\tau) F$. But if the other firm applies for leniency, firm applies as well if:

$$
-F<-\frac{1}{2} F+\frac{1}{2}(1-\tau) F-k \Leftrightarrow k<\frac{1}{2}(2-\tau) F
$$

A firm has more incentives to apply for leniency if the other firm does the same thing: leniency applications are strategic complements. There is no range of parameters for which only one firm applies for leniency (if we restrict to Nash equilibria in pure strategies).

Facing the other firm not applying for leniency, a firm playing the $M c$ strategy obtains an expected gain of $(1-\tau) F-k$ if it launches an internal audit and applies for leniency and $\widetilde{\Pi}_{i}$ if it continues to collude in the second market. A CEO applies for leniency if:

$$
(1-\tau) F-k \geq \widetilde{\Pi}_{i} \Leftrightarrow k \leq \frac{\{[1-\delta(1-\rho)](1-\tau)+\rho\} F-\widetilde{\pi}_{i}^{c}}{1-\delta(1-\rho)} \Leftrightarrow F \geq \frac{\widetilde{\pi}_{i}^{c}+[1-\delta(1-\rho)] k}{[1-\delta(1-\rho)](1-\tau)+\rho} \equiv F_{\text {report }}
$$

An higher value of $k$ yields to an increased value of $F_{\text {report }}$ and makes the $M c$ strategy easier to sustain. It is straightforward to see that if a firm benefits from applying for leniency then the other firm benefits too. ${ }^{40}$ Again leniency applications are strategic complements.

Scenario S+: We obtain the following comparative static properties modifying the value of $k$. Starting from the figure 4 (in the section 5.1) established for $k=0$ the border line $F_{3}$ moves to the left with an increased value of $k$. The $U_{\text {sim }}$ area is increased unlike the $M s$ area. The border line $F_{\text {report }}$ moves upward: the $M c$ area is increased unlike the $M s$ and $U_{\text {sim }}$ areas. Finally the border line $F_{M s}$ moves downward: the No Collusion and $U_{\text {seq }}$ areas are increased unlike the $M s$ area.

So anticompetitive effects are generated by an increased value of $k$ : the switch from $M s$ to $M c$ yields to longer lasting collusion and the switch from $M s$ to $U_{\text {sim }}$ increases collusive prices. But pro competitive effects may exist too. Firstly the switch from $U_{\text {sim }}$ to $M c$ yields to lower collusive prices (but the collusion is longer lasting). Secondly collusion can be no longer sustainable for some range of parameters whereas firms played the $M s$ strategy when $k=0$. For these values the AP seem to be too generous: the beneficiary firm obtains a reduced fine of $(1-\tau) F$ whereas it was willing to apply for leniency for a really low reduced fine. The variable $k$ performs a similar role to a remedial tax: its increase shall reduce the too much generous amount of the AP.

The impacts of $k$ on the border lines $F_{3}$ and $F_{M s}$ are non-monotonic. If $k$ is really high then firms playing the $M s$ strategy stop applying for leniency for the second cartel once the first one has been discovered. The expected profit under the $M s$ strategy is then sharply increased resulting in a switch of the border line $F_{3}$ to the right and a switch of the border line $F_{M s}$ upward. Then decentralized firms wish to commit to a

40

$$
\frac{\{[1-\delta(1-\rho)](1-\tau)+\rho\} F-\widetilde{\pi}_{i}^{c}}{1-\delta(1-\rho)} \leq \frac{1}{2}(2-\tau) F \Leftrightarrow 2\left(\widetilde{\pi}_{i}^{c}-\rho F\right) \geq-[1-\delta(1-\rho)] \tau F
$$

The left-hand side must be positive in order $M c$ be sustainable. The right side is negative and so this inequality is always checked. 
prohibitive value of $k$ since it provides the same impact as $\sigma=0$ (and firms collectively prefer $\sigma=0$ to $\sigma>0)$.

Scenario L+: There are fewer effects in scenario L+. For low values of $k$ the area $M s$ disappears. The only effect of an increased value of $k$ is then to switch the border line $M c$ upward resulting in an increased $M c$ area unlike the $U_{\text {sim }}$ area (considering the figure 5). Then collusion is longer-lasting but collusive prices are lower. For very high values of $k$ firms playing the $M s$ strategy stop applying for leniency for the second cartel once the first one has been discovered. The expected profit under the $M s$ strategy is increased and exceeds the profit under the $U_{\text {sim }}$ strategy for low values of $d$ : the $M s$ area re-emerges.

\section{Conclusion}

In a previous work we proved that firms engaged in multimarket collusive agreements may find it advantageous to compartmentalize their collusive agreements to defeat the risk of a single investigation ending up as a multiple investigation. In this article we prove that the antitrust authority may defeat this strategy using the leniency programs. In scenario S (Short investigation) decentralized firms never reveal the second cartel once the first one has been discovered. The amnesty plus are needed to induce the CEOs to launch internal investigations in order to obtain hard evidences of the second cartel and reveal it to the antitrust authority. In scenario L (Long investigation) the antitrust authority should also propose the amnesty plus to ensure that decentralized firms cooperate when the compartmentalization is perfect $\left(\mu_{3}=0\right)$. By contrast in the case of imperfect compartmentalization $\left(\mu_{3}>0\right)$ the amnesty plus is not necessary to induce decentralized firms to reveal the second cartel once the first one has been discovered. So the simple leniency programs are not sufficient to prevent firms to hide cartels with the compartmentalization. In order to be effective, these leniency programs should be linked with research efforts of the other cartel $\left(\mu_{3}>0\right)$ or with the presence of amnesty plus.

However, these leniency programs that defeat the decentralization strategy may lead to anticompetitive effects. In some cases they can strengthen the collusive opportunities for centralized firms. In scenario L the second cartel is always detected for the centralized firms (when $\mu_{2}=1$ ). Firms cooperate with antitrust authority by applying for leniency but the revealed evidence would have been discovered anyway by the authority. The leniency programs improve the timeliness of investigations but do not provide new evidences. The pro-collusive impacts of the leniency programs under scenario L are reinforced in the presence of amnesty plus. In addition the leniency programs have procollusive impact if they induce firms to switch from the $M s$ strategy to the $U_{\text {sim }}$ one (this may occur in the scenarios L and $\mathrm{S}+$ and systematically happens in scenario $\mathrm{L}+$ ). The modification of internal organization induces higher collusive prices without affecting the duration of the collusive agreement. The antitrust authority may be induced to drive firms to switch from the $M s$ strategy to the $U_{\text {sim }}$ one in order to increase the number of detected cartels and the global amount of fines. But collusion is more harmful socially since collusive prices are higher. Furthermore the resources devoted to processing various leniency applications by the centralized firms can be seen as a waste as they are devoted 
to fight cartels which would be dissolved without the antitrust authority investigation.

Obtaining procompetitive effects with the applications of leniency programs without generating procollusive impacts seems to be a sensitive task for the antitrust authority. This paper addresses some suggestions to design the leniency programs dedicated for multiproduct firms. Granting total immunity for the second cartel whereas the firm is under investigation for the first one often does not appear optimal in our model. In scenario L a decreased amount of fine is sufficient to induce firms playing the $U_{\text {sim }}$ or $U s$ (if $\mu_{2}<1$ ) strategy or the $M s$ strategy (if $\mu_{3}>0$ ) to reveal the second cartel. In this case granting total immunity is too generous. It must be used only when firms play the $M c$ or the $U c$ strategy. But the $M c$ strategy appears only when $d$ is low or $F$ is low and the other strategy only for low values of $F$ and $\mu_{2}$. So granting total immunity for the second cartel must be proposed only when products are weak substitutes and when the capacities of authority investigations are low (low values of $\mu_{2}$ or $\mu_{3}$ ). In the other cases partial amnesty is sufficient to induce firms to collaborate with the authority. By contrast when the investigation for the first cartel is completed it seems to be recommended to propose the total immunity for the second cartel if it is revealed and it might be appropriate to offer the amnesty plus program. We would be close to scenario $\mathrm{S}+$ that helps fight against the $M s$ strategy without encouraging collusion for very centralized firms.

We study in section 6 several extensions to check the robustness of the results. Other variants can be explored in future research. In section 6.3 we note that firms can choose a decentralized organization in order to slow down the authority investigations which allows them to apply for leniency for the second cartel. We could also assume that centralized firms can make the leniency application faster than decentralized firms. Together firms could prefer a decentralized structure to slow down the authority investigations but individually firms may have an interest in more centralization to be the first to apply for leniency.

This paper does not address the role of asymmetric information among the firms about the progress of investigations. This could be achieved by following Harrington (2013). A centralized organization could reduce asymmetric information by facilitating the flow of information inside the firm about a potential opening of investigations onto adjacent markets. On the other hand, divisions inside decentralized firms could have a delay or could imperfectly observe the investigation on other division. So asymmetric information could be observed only for decentralized firms. In the same idea decentralized firms could be more subject than centralized firms to bluff attempts by competition authority as in Sauvagnat (2015).

The above-mentioned cartels concerning household goods drive another interesting topic for future research. These cartels have been developed in the context of vertical relation between suppliers and distributors. In this case the choice of organizational structure can be affected by the suppliers if they ask for centralized bargaining or if they agree to individual bargaining for each product. Suppliers could require centralized bargaining to avoid the risk of collusion or individual bargaining to decrease the collusive price in the case collusion is particularly difficult to remove. Snyder (1996) shows that it is in the interest of the buyers to bundle over time their purchases in order to increase the fluctuations in demand and to destabilize the cartels. In the proposed extension suppliers could try to modify the organization of the pricing negotiations to affect the organizational structure of the cartels and to destabilize them. 


\section{References}

[1] AUBERT Cécile, Patrick REY and William E. KOVACIC (2006), The impact of leniency and whistleblowing programs on cartels, International Journal of Industrial Organization, 24, 1241-1266.

[2] Autorité de la concurrence (2014), Etude relative au programme de clémence français, mimeo.

[3] BACCARA Mariagiovanna and Heski BAR-ISAAC (2008), How to Organize Crime, Review of Economic Studies, 75, 1039-1067.

[4] BAKER Wayne E. and Robert R. FAULKNER (1993), The social organization of conspiracy: illegal networks in the heavy electrical equipment industry, American Sociological Review, 58 (6), 837-860.

[5] BRENNER Steffen (2009), An empirical study of the European corporate leniency program, International Journal of Industrial Organization, 27, 639-645.

[6] CHOI Jay Pil and Heiko GERLACH (2013), Multi-Market Collusion with Demand Linkages and Antitrust Enforcement, Journal of Industrial Economics, 61 (4), 987-1022.

[7] CONNOR John M. (1997), The global lysine price-fixing conspiracy of 1992-1995, Review of Agricultural Economics, 19, 412-427.

[8] DARGAUD Emilie and Armel JACQUES (2015) Hidden collusion by decentralization: firm organization and antitrust policy, Journal of Economics, 114 (2), 153-176.

[9] GAROUPA Nuno (2007), Optimal law enforcement and criminal organization, Journal of Economic Behavior and Organization, 63, 461-474.

[10] HAMMOND Scott D. (2009), Cornerstones of an effective leniency program, address at an International Competition Network workshop, Sydney, Australia (November 22-23, 2004).

[11] HARRINGTON Joseph E.Jr. (2004), Cartel pricing dynamics in the presence of an antitrust authority, Rand Journal of Economics, 35 (4), 651-673.

[12] HARRINGTON Joseph E.Jr. (2005), Optimal cartel pricing in the presence of an antitrust authority, International Economic Review, 46 (1), 145-169.

[13] HARRINGTON Joseph E.Jr. (2008), Optimal corporate leniency programs, Journal of Industrial Economics, 56 (2), 215-246.

[14] HARRINGTON Joseph E.Jr. (2011), When is an antitrust authority not aggressive enough in fighting cartels?, International Journal of Economic Theory, 7, 39-50.

[15] HARRINGTON Joseph E.Jr. (2013), Corporate leniency programs when firms have private information: the push of prosecution and the pull of pre-emption, Journal of Industrial Economics, 61 (1), 1-27. 
[16] HARRINGTON Joseph E.Jr. and Myong-Hun CHANG (2012), Endogenous antitrust enforcement in the presence of a corporate leniency program, mimeo.

[17] HOUBA Harold, Evgenia MOTCHENKOVA and Quan WEN (2012), Competitive prices as optimal cartel prices, Economics Letters, 114, 39-42.

[18] LEFOUILI Yassine and Catherine ROUX (2012), Leniency programs for multimarket firms: the effect of amnesty plus on cartel formation, International Journal of Industrial Organization, 30, 624-640.

[19] MARX Leslie M., Claudio MEZZETTI and Robert C. MARSHALL (2015), Antitrust leniency with multiproduct colluders, American Economic Journal: Microeconomics, 7 (3), 205-240.

[20] MILLER Nathan H. (2009), Strategic leniency and cartel enforcement, American Economic Review, 99 (3), 750-768.

[21] MOTTA Massimo and Michele POLO (2003), Leniency programs and cartel prosecution, International Journal of Industrial Organization, 21 (3), 347-379.

[22] PERSICO Nicola (2002), Racial profiling, fairness, and effectiveness of policing, American Economic Review, 92 (5), 1472-1497.

[23] ROUX Catherine and Thomas Von UNGERN-STERNBERG (2007), Leniency programs in a multimarket setting: amnesty plus and penalty plus, mimeo.

[24] SAUVAGNAT Julien (2014), Are leniency programs too generous?, Economics Letters, 123, 323-326.

[25] SAUVAGNAT Julien (2015), Prosecution and leniency programs: the role of bluffing in opening investigations, Journal of Industrial Economics, 63 (2), 313-338.

[26] SNYDER Christopher M. (1996), A dynamic theory of countervailing power, Rand Journal of Economics, 27 (4), 747-769.

[27] SOUAM Saïd (2001), Optimal antitrust policy under different regimes of fines, International Journal of Industrial Organization, 19, 1-26.

[28] SPAGNOLO Giancarlo (2005), Divide et Impera: Optimal leniency programs, mimeo.

[29] SPAGNOLO Giancarlo (2008), Leniency and whistleblowers in antitrust, in Paolo Buccirossi (ed), Handbook of antitrust economics, MIT Press. 